\title{
Tin dioxide nanomaterial-based photocatalysts for nitrogen oxide oxidation: a review
}

\author{
Viet Van Pham ${ }^{*}$, Hong-Huy Tran ${ }^{1}$, Thao Kim Truong ${ }^{1}$ and Thi Minh Cao ${ }^{2}$
}

Review

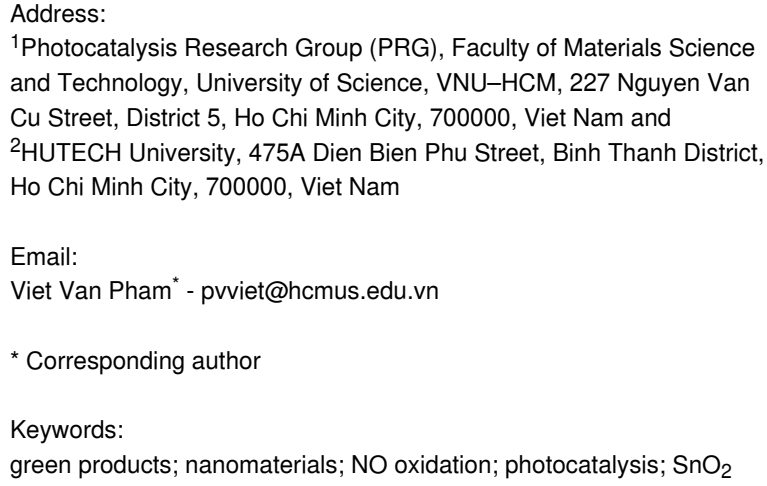

${ }^{1}$ Photocatalysis Research Group (PRG), Faculty of Materials Science and Technology, University of Science, VNU-HCM, 227 Nguyen Van Cu Street, District 5, Ho Chi Minh City, 700000, Viet Nam and ${ }^{2}$ HUTECH University, 475A Dien Bien Phu Street, Binh Thanh District, Ho Chi Minh City, 700000, Viet Nam

Email:

Viet Van Pham* - pvviet@hcmus.edu.vn

${ }^{*}$ Corresponding author

Keywords:

green products; nanomaterials; $\mathrm{NO}$ oxidation; photocatalysis; $\mathrm{SnO}_{2}$

Beilstein J. Nanotechnol. 2022, 13, 96-113.

https://doi.org/10.3762/bjnano.13.7

Received: 07 October 2021

Accepted: 30 December 2021

Published: 21 January 2022

This article is part of the thematic issue "Nanomaterials for photocatalysis and applications in environmental remediation and renewable energy".

Associate Editor: C. T. Yavuz

(C) 2022 Van Pham et al.; licensee Beilstein-Institut. License and terms: see end of document.

\begin{abstract}
Semiconducting $\mathrm{SnO}_{2}$ photocatalyst nanomaterials are extensively used in energy and environmental research because of their outstanding physical and chemical properties. In recent years, nitrogen oxide $\left(\mathrm{NO}_{x}\right)$ pollutants have received particular attention from the scientific community. The photocatalytic $\mathrm{NO}_{x}$ oxidation will be an important contribution to mitigate climate change in the future. Existing review papers mainly focus on applying $\mathrm{SnO}_{2}$ materials for photocatalytic oxidation of pollutants in the water, while studies on the decomposition of gas pollutants are still being developed. In addition, previous studies have shown that the photocatalytic activity regarding $\mathrm{NO}_{x}$ decomposition of $\mathrm{SnO}_{2}$ and other materials depends on many factors, such as physical structure and band energies, surface and defect states, and morphology. Recent studies have been focused on the modification of properties of $\mathrm{SnO}_{2}$ to increase the photocatalytic efficiency of $\mathrm{SnO}_{2}$, including bandgap engineering, defect regulation, surface engineering, heterojunction construction, and using co-catalysts, which will be thoroughly highlighted in this review.
\end{abstract}

\section{Review}

\section{Introduction}

A World Health Organization (WHO) report indicated that 4.2 million deaths every year occur due to exposure to ambient (outdoor) air pollution [1]. This number is much higher than the deaths from the COVID-19 pandemic in the past year. WHO also reported that the emissions of nitrogen oxides in the early 1980 s over the world were estimated at approximately
$150 \times 10^{12} \mathrm{~g} /$ year while the concentration of nitrogen dioxide outdoor can achieve up to $940 \mu \mathrm{g} / \mathrm{m}^{3}(0.5 \mathrm{ppm})$ for $30 \mathrm{~min}$ and $400 \mu \mathrm{g} / \mathrm{m}^{3}(0.21 \mathrm{ppm})$ for $60 \mathrm{~min}$ [2]. Nitrogen oxides $\left(\mathrm{NO}_{x}\right.$, including $\mathrm{NO}$ and $\mathrm{NO}_{2}$ ) are poisonous and highly reactive gases. Nitrogen dioxide $\left(\mathrm{NO}_{2}\right)$ is associated with respiratory diseases and mortality. $\mathrm{NO}_{x}$ is formed when fuel is burnt at high temper- 
atures and emitted by automobiles, trucks, and various non-road vehicles (e.g., construction equipment, boats) and industrial sources such as power plants, industrial boilers, cement kilns, and turbines [3]. In addition, diesel vehicles are considered a primary $\mathrm{NO}_{x}$ emission source causing adversely impacts on environment and human health, such as acid rain, global warming, and respiratory diseases in humans (Figure 1a). $\mathrm{NO}_{x}$ pollution damages lung cells and reacts with molecules in the air when released into the ozone layer. $\mathrm{NO}_{x}$ can aggravate respiratory diseases such as asthma, bronchitis, and cardiovascular diseases. When humans are exposed to $\mathrm{NO}_{2}$ at concentrations of over $200 \mu \mathrm{g} / \mathrm{m}^{3}$, even for periods of time, this will cause adverse effects on the respiratory system. Some studies have shown that $\mathrm{NO}_{2}$ concentrations over $500 \mu \mathrm{g} / \mathrm{m}^{3}$ can cause acute health effects. Although the lowest threshold for $\mathrm{NO}_{2}$ exposure with a direct effect on lung function in asthmatic subjects was $560 \mu \mathrm{g} / \mathrm{m}^{3}, \mathrm{NO}_{2}$ exposure to concentrations over $200 \mu \mathrm{g} / \mathrm{m}^{3}$ caused pulmonary responses in asthmatic people [4,5]. Guillaume $\mathrm{P}$. Chossière et al. indicated that reducing $\mathrm{NO}_{x}$ in the air will significantly reduce the risk of death in humans demonstrated through a study on lockdowns during the COVID-19 pandemic in China that led to a reduction of $\mathrm{NO}_{2}, \mathrm{O}_{3}$, and $\mathrm{PM}_{2.5}$ concentrations globally, resulting in ca. 32,000 avoided premature mortalities, including ca. 21,000 in China [6]. Therefore, the control, treatment, and conversion of $\mathrm{NO}_{x}$ to green products greatly interested the scientific community in recent years.

There are many methods for controlling and removing $\mathrm{NO}_{x}$, such as reducing the burning temperature, reducing the residence time at peak temperature, chemical reduction or oxidation of $\mathrm{NO}_{x}$, removal of nitrogen from combustion fuels, and sorption, both adsorption and absorption [7,8]. Among them, photocatalytic oxidation is an efficient method of converting $\mathrm{NO}_{x}$ into nitrate $\left(\mathrm{NO}_{3}{ }^{-}\right)$ions. The removal of $\mathrm{NO}_{3}{ }^{-}$ions is easy, efficient, and economic through chemical or biological methods such as the conversion of $\mathrm{NO}_{3}{ }^{-}$to $\mathrm{N}_{2}$ by aerobic microorganisms $[9,10]$. Figure $1 \mathrm{~b}$ illustrates the working scheme of semiconductor photocatalysts for NO oxidation. Light generates holes $\left(\mathrm{h}^{+}\right)$in the valence band (VB) and electrons $\left(\mathrm{e}^{-}\right)$in the conduction band $(\mathrm{CB})$ of the photocatalytic material. Electrons at the material surface will react with oxygen molecules to form superoxide radicals $\left({ }^{\circ} \mathrm{O}_{2}{ }^{-}\right.$, similarly holes react with water to form hydroxyl radicals). Free radicals and strong oxidizing agents react with $\mathrm{NO}_{x}$ to produce $\mathrm{NO}_{3}{ }^{-}$, deposited on the photocatalyst surface. The $\mathrm{NO}_{3}{ }^{-}$product formed on the surface of the catalyst can be easily separated for further treatment by washing with water due [11] (see Equations 1-10).

$$
\begin{gathered}
\text { Semiconductor }+h v \rightarrow \text { Semiconductor }\left(\mathrm{h}_{\mathrm{VB}}^{+}+\mathrm{e}_{\mathrm{CB}}^{-}\right) \\
\mathrm{O}_{2}+\mathrm{e}_{\mathrm{CB}}^{-} \rightarrow{ }^{\bullet} \mathrm{O}_{2}^{-} \\
\mathrm{H}_{2} \mathrm{O}+\mathrm{h}_{\mathrm{VB}}^{+} \rightarrow \mathrm{HO}^{\bullet}+\mathrm{H}^{+} \\
\bullet \mathrm{O}_{2}^{-}+\mathrm{H}_{2} \mathrm{O} \rightarrow \mathrm{HO}_{2}^{\bullet}+\mathrm{OH}^{-} \\
2^{\bullet} \mathrm{HO}_{2} \rightarrow \mathrm{O}_{2}+\mathrm{H}_{2} \mathrm{O}_{2} \\
\mathrm{HO}_{2}^{\bullet}+\mathrm{H}_{2} \mathrm{O}+\mathrm{e}_{\mathrm{CB}}^{-} \rightarrow \mathrm{H}_{2} \mathrm{O}_{2}+\mathrm{OH}^{-}
\end{gathered}
$$

(a)

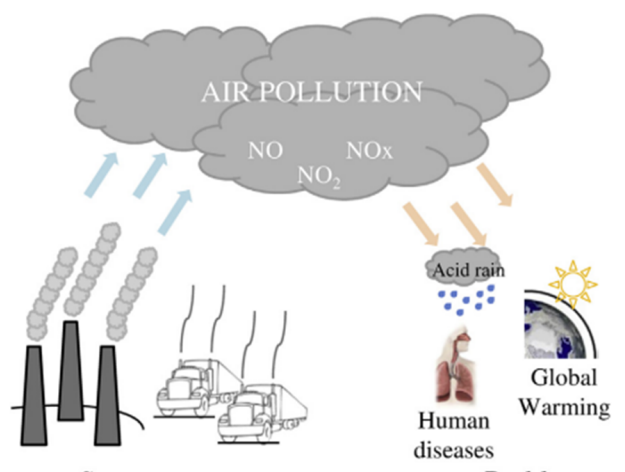

Sources

Problems

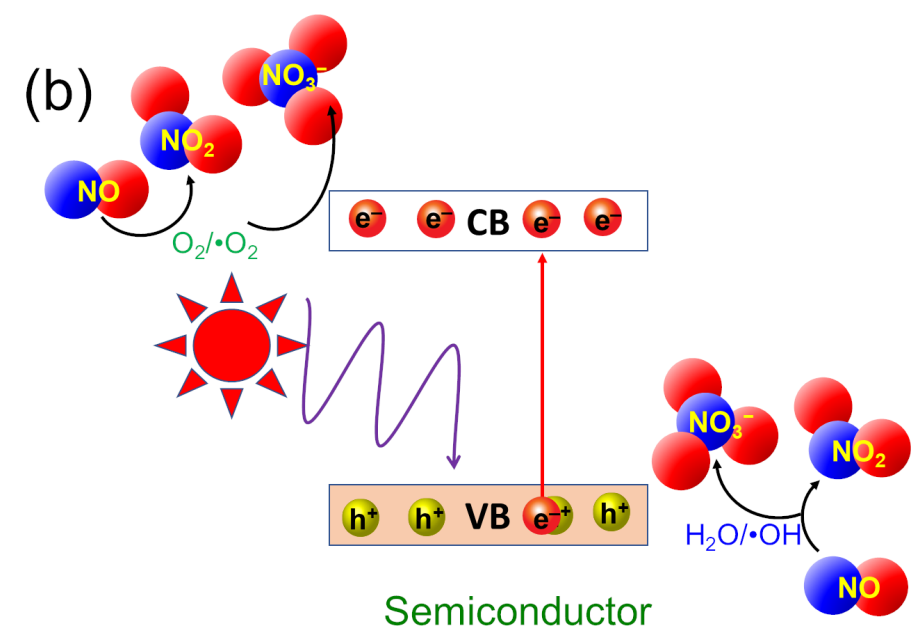

Figure 1: Problems and sources associated with $\mathrm{NO}_{x}$ air pollution (a) and NO photocatalysis over a semiconductor (b). Figure 1a was reprinted from [12], Journal of Environmental Management, vol. 129, by J. Ângelo; L. Andrade; L. M. Madeira; A. Mendes "An overview of photocatalysis phenomena applied to $\mathrm{NO}_{\mathrm{x}}$ abatement", pages 522-539, Copyright (2013), with permission from Elsevier. This content is not subject to CC BY 4.0. 


$$
\begin{gathered}
2^{\bullet} \mathrm{O}_{2}^{-}+2 \mathrm{H}_{2} \mathrm{O} \rightarrow 2 \mathrm{H}_{2} \mathrm{O}_{2}+\mathrm{O}_{2} \\
\mathrm{H}_{2} \mathrm{O}_{2}+\mathrm{e}_{\mathrm{CB}}^{-} \rightarrow{ }^{\bullet} \mathrm{OH}+\mathrm{OH}^{-} \\
\mathrm{NO}+{ }^{\bullet} \mathrm{O}_{2}^{-} \rightarrow \mathrm{NO}_{3}^{-} \\
\mathrm{NO}+2 \mathrm{HO}^{\bullet} \rightarrow \mathrm{NO}_{2}+\mathrm{H}_{2} \mathrm{O}
\end{gathered}
$$

Recently, research on tin dioxide $\left(\mathrm{SnO}_{2}\right)$ materials has increased significantly, which expresses the potential of $\mathrm{SnO}_{2}$ materials for the scientific community (Figure 2a). $\mathrm{SnO}_{2}$ is one of the most extensively investigated n-type semiconductors. It is known as tin(VI) oxide or stannic oxide (not to be confused with stannous oxide with tin in the oxidation state of $2+$ [13] also known as cassiterite [14]. $\mathrm{SnO}_{2}$ materials have many interesting properties. For instance, the structure and electronic structure can be manipulated easily due to the highly tunable valence state and oxygen vacancy defects (OVs) $[15,16]$. Therefore, $\mathrm{SnO}_{2}$ is considered a potential material in various technological fields such as catalysis, optoelectronic devices, rechargeable lithium batteries, electrocatalysis, photocatalysis, solar energy conversion, and gas sensing [17-24]. In the catalytic area, $\mathrm{SnO}_{2}$ is an emerging material for removing contaminants such as organic dyes, phenolic compounds, and volatile organic compounds (VOCs) due to strongly oxidizing properties thanks to flexible energy band structure, rich defects, good chemical, and high thermal stability, and easily controlled morphology [25-30]. However, pure $\mathrm{SnO}_{2}$ suffers from some inherent drawbacks that limit its practical applications. With a wide bandgap $(3.5-3.7 \mathrm{eV})[31,32], \mathrm{SnO}_{2}$ can only be excited by UV irradiation. As a typical oxidation photocatalyst with the $\mathrm{CB}$ edge energy level, which is not conducive to the reduction of $\mathrm{O}_{2}$ to ${ }^{\cdot} \mathrm{O}_{2}{ }^{-}[31,33]$ and the rapid recombination rate of photoinduced electron-hole pairs [34], the photocatalytic ability of $\mathrm{SnO}_{2}$ is less efficient than that of other semiconductor photocatalysts (Figure 2b). Despite literature relating to the unfavorable CB edge of $\mathrm{SnO}_{2}$, many reports still proposed its photocatalytic behaviors partly based on ${ }^{\circ} \mathrm{O}_{2}{ }^{-}$species via the combination of experimental physicochemical analyses, such as electron spin resonance (ESR) spectroscopy, active species trapping experiments, valence band X-ray photoelectron spectroscopy (XPS), and diffuse reflectance spectroscopy (DRS) [35-40]. This promotes a new avenue for diverse analyses of semiconductor photocatalysts in addition to the traditional theories and conclusions.

Previous studies have shown that the photocatalytic activity of $\mathrm{NO}_{x}$ decomposition of materials in general and $\mathrm{SnO}_{2}$ depends on many factors, including the structure and energy band, surface and defect states, morphology, etc. For that reason, recent studies are being focused on the modification of properties of $\mathrm{SnO}_{2}$ to upgrade the photocatalytic efficiency of $\mathrm{SnO}_{2}$, including bandgap engineering, defect regulation, surface engineering, heterojunction construction, co-catalyst, which will be thoroughly outlined in this review.

\section{Structure and bandgap}

$\mathrm{SnO}_{2}$ has a crystal structure similar to that of rutile $\mathrm{TiO}_{2}$ $[41,42]$. The unit cell parameters of rutile $\mathrm{SnO}_{2}$ are $a=b=0.47374 \mathrm{~nm}$ and $c=0.31864 \mathrm{~nm}$ [43]. In one unit cell of rutile $\mathrm{SnO}_{2}, \mathrm{a} \mathrm{Sn}^{4+}$ ion is bonded to six oxygen ions, and every oxygen atom is coordinated by three $\mathrm{Sn}^{4+}$ ions, forming a $(6,3)$ coordination structure [44]. When $\mathrm{SnO}_{2}$ materials are prepared as thin films with two to eight layers the bandgap is larger than that of bulk $\mathrm{SnO}_{2}$ and decreases with increasing film thickness [45]. Zhou et al. indicated that the direct bandgap transition of $\mathrm{SnO}_{2}$ has an absorption coefficient $\alpha$ and the optical bandgap $\left(E_{\mathrm{g}}\right)$ can be determined by the calculation of (a)

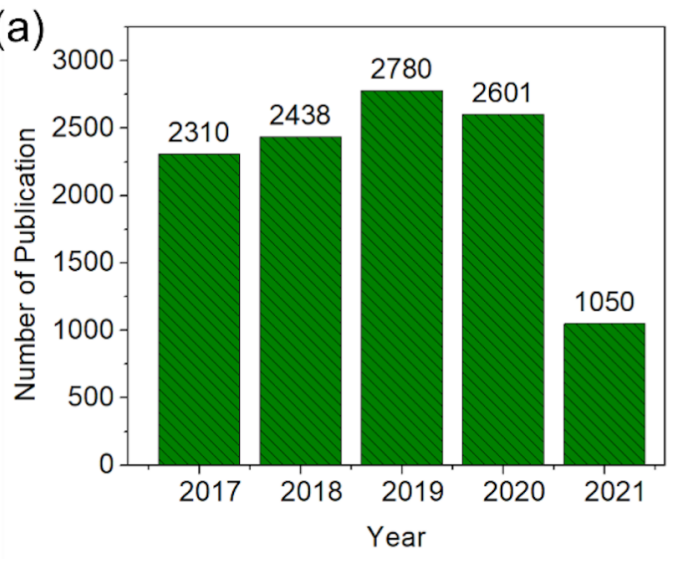

(b)

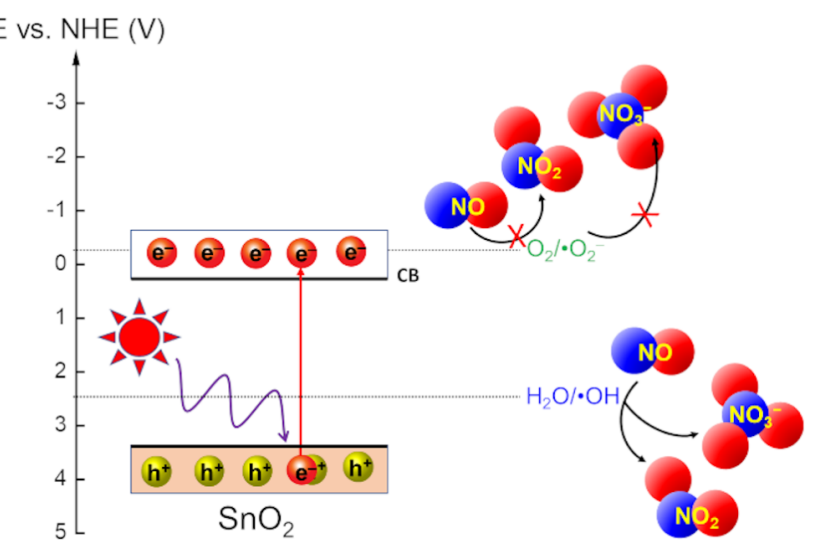

Figure 2: (a) Statistics of publication number on $\mathrm{SnO}_{2}$ materials (2017-06/2021). Data was extracted from Web of Science, Clarivate Analytics; (b) NO photocatalytic oxidation ability of $\mathrm{SnO}_{2}$. 
$\alpha(h v)^{2} \propto\left(h v-E_{\mathrm{g}}\right)^{1 / 2} / h v$, and the plot of $\alpha(h v)^{2}$ vs photon energy $h v$, respectively. For example, the bandgap of a $\mathrm{SnO}_{2}$ thin film with a thickness of about $130 \mathrm{~nm}$ is $3.597 \mathrm{eV}$ [42].

The reported bandgap of bulk $\mathrm{SnO}_{2}$ is $3.6 \mathrm{eV}$. Changing the morphology, particle size, or the formation of OVs or defects narrow the bandgap. In the study of Babu et al., a redshift of the absorption edge was observed when $\mathrm{SnO}_{2}$ quantum dots (SQDs) were heated from 200 to $700{ }^{\circ} \mathrm{C}$, which indicated that the bandgap of the SQDs decreased from 3.49 to $2.52 \mathrm{eV}$ (for SQD-700) as shown in Figure 3. These results demonstrated that the redshift is favorable for a photocatalytic activity in the visible light region.

Meanwhile, Fan et al. [47] investigated the bandgap of $\mathrm{SnO}_{2}$ when changing the self-doping of $\mathrm{SnO}_{2}$. The change of the color of the powder products and the redshift in the absorption spectra are two quantities that are correlated with each other. Normally, $\mathrm{SnO}_{2}$ is white and optical absorptions in the visible region arise from changes of the band structure. Moreover, the bandgap of $\mathrm{SnO}_{2-x}$ self-doped with $\mathrm{Sn}^{2+}$ can be easily determined as follows: A straight line to the $x$-axis, equaling to the extrapolated value of $E_{\text {photon }}$ at $\alpha=0$, gives the absorption edge energy. This energy parameter corresponds to the bandgap $\left(E_{\mathrm{g}}\right)$ of the material [47].

\section{Surface and defect states}

Structural defects and lattice imperfections usually bestow most of the properties exploited for applications of $\mathrm{SnO}_{2}$ materials as they influence various physicochemical properties and reactions on the surface. Most important are defect states of materi- als, including predominantly point defects, that is, defects associated with one lattice point, such as cation or oxygen ion vacancies. OVs determine the physical and chemical properties of metal oxides. Figure 4a shows the natural crystal structure of $\mathrm{SnO}_{2}$ synthesized by vapor transport [48]. The (110) plane of rutile $\mathrm{SnO}_{2}$ is the most common surface, and it is also thermodynamically the most stable [48]. In the rutile phase of $\mathrm{SnO}_{2}$ in Figure $4 \mathrm{~b}$, the (110) plane contains all surface bridging oxygens (1), bridging OVs (2), and oxygen coordinated three- or fivefold $(3,4)$ with surface tin atoms (Sn 5f). The dual valency of $\mathrm{Sn}$ at the surface of $\mathrm{SnO}_{2}$ plays a role in the reversible transformation of the surface composition from $\mathrm{Sn}^{4+}$ cations to $\mathrm{Sn}^{2+}$, which leads to active centers in the surface chemical process [48]. Moreover, the OVs in $\mathrm{SnO}_{2}$ often appear when it is synthesized by chemical methods such as sol-gel, hydrothermal, and microwave synthesis [49-51]. The formation and concentration of OVs depend on particle size, synthesizing temperature, and morphology of $\mathrm{SnO}_{2}$. The OVs play the role of an electron donor and provide free electrons, making $\mathrm{SnO}_{2}$ an n-type semiconductor [52].

Guoliang Xu et al. indicated that NO could be absorbed easily on various $\mathrm{SnO}_{2}(110)$ surfaces, and it is preferentially adsorbed on the OV site through an N-down orientation. Figure 5 shows the calculation of the energy of $\mathrm{NO}$ conversion processes on $\mathrm{SnO}_{2}(110), \mathrm{SnO}_{2-x}(110)$, and $\mathrm{O}_{2}+\mathrm{SnO}_{2-x}(110)$ surfaces. The oxidation of $\mathrm{NO}$ on other surfaces is determined by the reaction energies, as shown in Figure 5. The $\mathrm{O}_{2}+\mathrm{SnO}_{2-x}(110)$ surface is more exothermic and preferable than other surfaces, which leads to an efficient reaction of $\mathrm{NO}$ with the $\mathrm{SnO}_{2}$ surface [54]. Also, Tiya-Djowe et al. [55] indicated that calcined $\mathrm{SnO}_{2}$ sam-
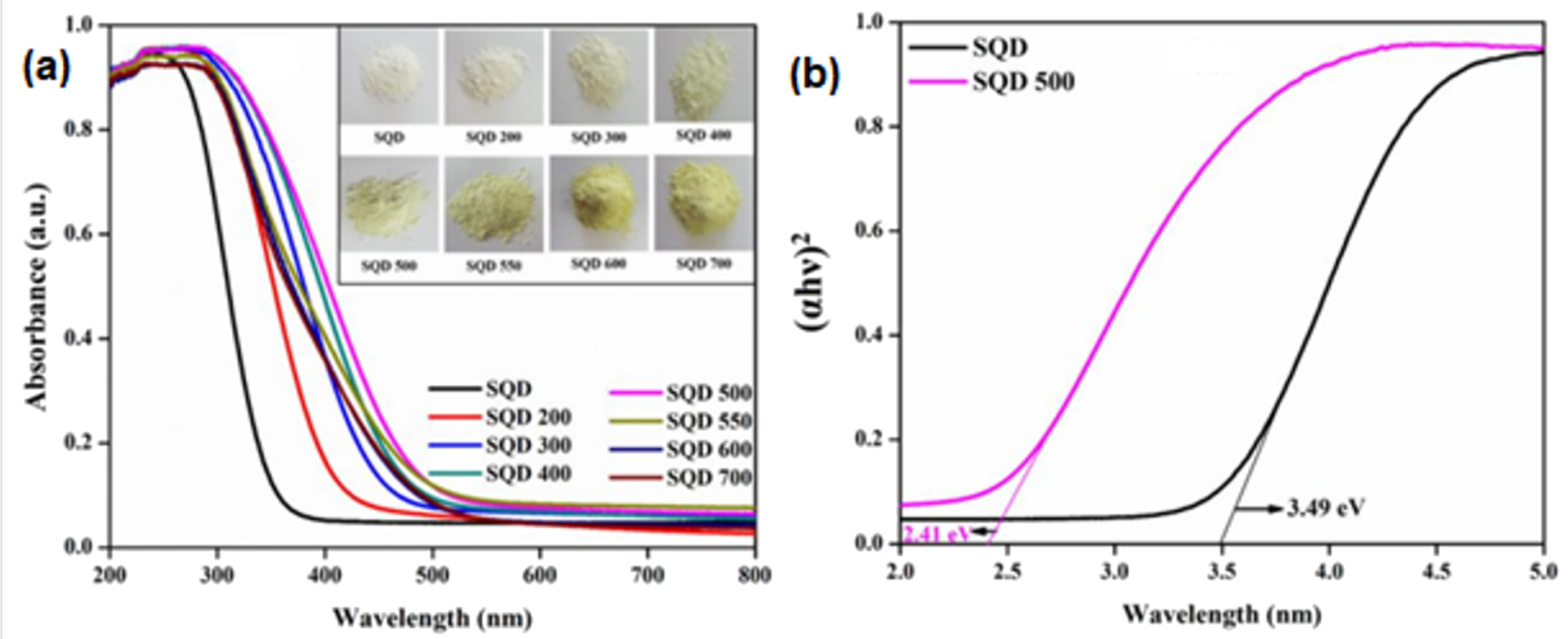

Figure 3: Ultraviolet-visible absorption spectra (a) and corresponding bandgaps of SQDs (b). Figure 3 was reprinted from [46], Materials Letters, vol. 221, by Babu, B.; Neelakanta Reddy, I.; Yoo, K.; Kim, D.; Shim, J. "Bandgap tuning and XPS study of SnO 2 quantum dots", pages 211-215, Copyright (2018), with permission from Elsevier. This content is not subject to CC BY 4.0. 
(a)

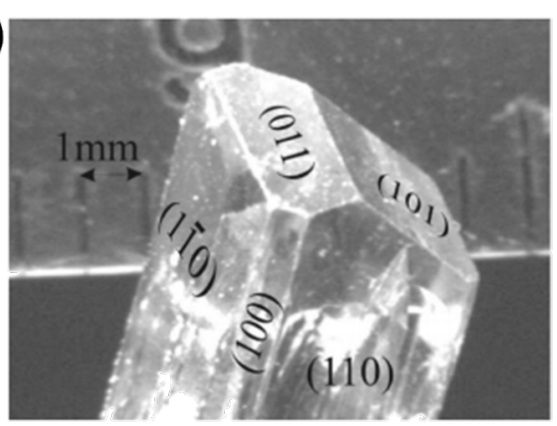

(b)

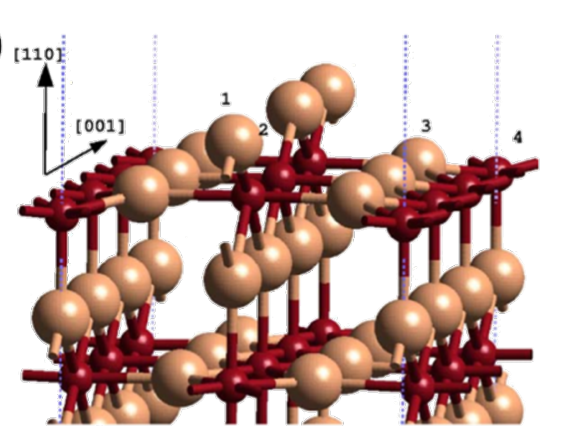

Figure 4: (a) Natural growth faces of $\mathrm{SnO}_{2}$ are the (110), (100) (equivalent to (010) in rutile), and (101) (equivalent to (011) in rutile) surfaces. Figure 4a was reprinted with permission from [48] (M. Batzill; K. Katsiev; J. M. Burst; U. Diebold; A. M. Chaka; B. Delley, Phys. Rev. B, vol. 72, article no. 165414,2005$)$. Copyright (2005) by the American Physical Society. This content is not subject to CC BY 4.0 ; (b) $\mathrm{SnO}_{2}(110)$ surface including a bridging oxygen vacancy (1-bridging oxygen; 2-bridging OV; 3-oxygen coordinated threefold with surface tin (Sn 5f); 4-oxygen coordinated fivefold with surface tin (Sn 5f). Figure 4b was reprinted from [53], Surface Science, vol. 577, by Mäki-Jaskari, M. A.; Rantala, T. T.; Golovanov, V. V. "Computational study of charge accumulation at $\mathrm{SnO}_{2}(110)$ surface", pages 127-138, Copyright (2005), with permission from Elsevier. This content is not subject to CC BY 4.0 .

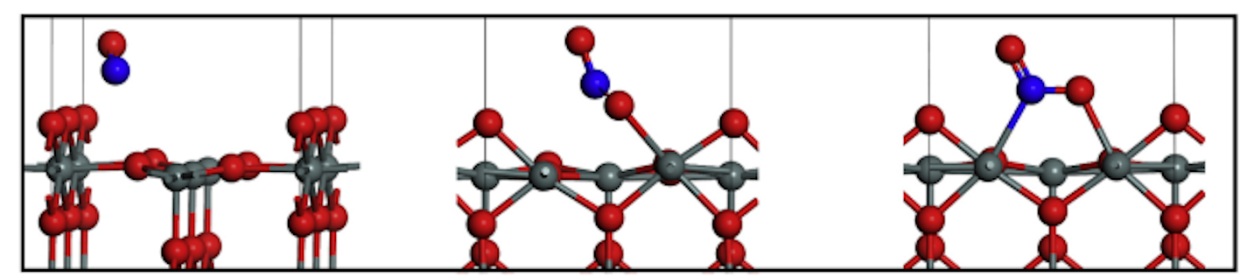

(a) $\mathrm{SnO}_{2}$

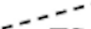
TS $2 \mathrm{I} .79 \mathrm{kcal} / \mathrm{mol}$ $14.05 \mathrm{kcal} / \mathrm{mol}$
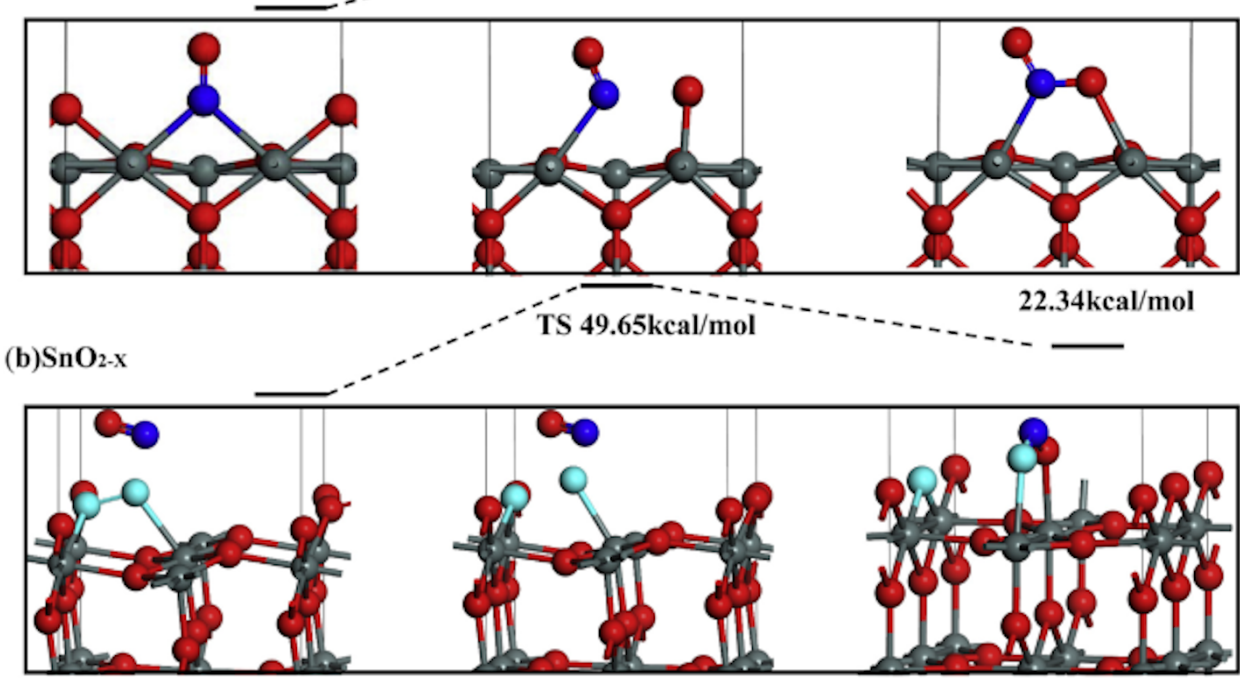

(c) $\mathrm{O}_{2}+\mathrm{SnO}_{2-\mathrm{X}}$

TS $5.01 \mathrm{kcal} / \mathrm{mol}$

$-42.41 \mathrm{kcal} / \mathrm{mol}$

Figure 5: The conversion processes of $\mathrm{NO}$ on perfect $\mathrm{SnO}_{2}(110), \mathrm{SnO}_{2-x}(110)$ and $\mathrm{O}_{2}+\mathrm{SnO}_{2-x}(110)$ surfaces. Figure 5 was reprinted from [54], Sensors and Actuators B: Chemical, vol. 221, by Xu, G.; Zhang, L.; He, C.; Ma, D.; Lu, Z. "Adsorption and oxidation of $\mathrm{NO}_{\text {on various SnO }}(110)$ surfaces: A density functional theory study", pages 717-722, Copyright (2015), with permission from Elsevier. This content is not subject to CC BY 4.0.

ples with higher OV density showed improved photocatalytic performances. Besides, the OV density contributes to the rise of the valence band maximum and a decrease of the bandgap energy of $\mathrm{SnO}_{2}$ materials.

\section{Morphology}

There are many shapes of $\mathrm{SnO}_{2}$, for example, nanoparticles, nanocubes, nanorods, nanosheets, nanospheres, nanobelts, and nanotubes. These morphologies can be controllably obtained by 
using polyvinylpyrrolidone (PVP), sodium dodecyl sulfonate (SDS), cetyl trimethyl ammonium bromide (CTAB), or tetrapropyl ammonium bromide (TPAB) as surfactants in a hydrothermal method [56-59]. The difference of morphologies will affect the properties of $\mathrm{SnO}_{2}$ regarding gas sensor activity and optical, electrical, and electrochemical properties [60-63] The typical properties of $\mathrm{SnO}_{2}$ are significantly affected by the effective surface area of different nanomaterial morphologies [63-65].

Wang et al. [66] synthesized $\mathrm{SnO}_{2}$ microspheres on a fluorine-doped tin oxide (FTO) substrate and the SEM images (Figure 6) show $\mathrm{SnO}_{2}$ microspheres with an average diameter of 2.0-2.5 $\mu \mathrm{m}$. By using $\mathrm{SnO}_{2}$ microsphere photocatalysts for the photocatalytic oxidation of NO, Le et al. [67] indicated that $3 \mathrm{D}$ hierarchical flower-like $\mathrm{SnO}_{2}$ microspheres exhibited a photocatalytic activity towards $\mathrm{NO}$ decomposition comparable to that of commercial $\mathrm{P} 25 \mathrm{TiO}_{2}$. Specifically, $\mathrm{SnO}_{2}$ microspheres can degrade $57.2 \%$ NO (1 ppm of initial concentration) under solar light. However, the photocatalytic mechanism of NO degradation has not been investigated [67]. Zhang et al. [68] found that the crystalline/amorphous stacking structure of $\mathrm{SnO}_{2}$ microspheres can moderate surface absorption competition between oxygen gas and $\mathrm{NO}$ gas, contributing to the generation of reactive oxygen species (ROS) to oxidize $\mathrm{NO}$ to $\mathrm{NO}_{3}{ }^{-}$ions. Huy et al. [69] synthesized $\mathrm{SnO}_{2} \mathrm{NPs}$, and this is the first report on using a $\mathrm{SnO}_{2}$ photocatalyst with NP morphology for the NO degradation. The photocatalytic mechanism of $\mathrm{SnO}_{2} \mathrm{NPs}$ is based on electrons and holes to generate reactive radicals. Figure 7 shows that the photocatalytic NO removal efficacy of $\mathrm{SnO}_{2}$ NPs achieved $63.37 \%$ after 30 min under solar light irra- diation, and the conversion efficacy from $\mathrm{NO}$ to $\mathrm{NO}_{2}$ is $1.66 \%$. The high photocatalytic performance and the stability of $\mathrm{SnO}_{2}$ NPs under solar light is promising for potential application [69].

\section{Recent approaches in the modification of $\mathrm{SnO}_{2}$ for photocatalytic $\mathrm{NO}_{x}$ oxidation}

Many attempts have been made to enhance the photocatalytic activity and take better advantage of $\mathrm{SnO}_{2}$ for the $\mathrm{NO}_{x}$ abatement, including the combination with other metal oxides [70], organic semiconductors [71], or metallic nanomaterials [72] to form a heterojunction/composite photocatalyst, and self-doping [73] or elemental doping [39,74]. Hybrid or doped photocatalysts ideally exhibit an improved photocatalytic efficacy due to the reduced recombination rate of photogenerated charge carriers and the lower activation energy. However, additional factors considerably affect the overall photocatalytic process. Table 1 shows a comparison of the NO photocatalytic oxidation ability of neat $\mathrm{SnO}_{2}$ and modified $\mathrm{SnO}_{2}$ materials. Recent studies on this material system mainly focus on modifying $\mathrm{SnO}_{2}$ toward the application in the visible light region.

\section{Charge transfer improvement}

The combination of $\mathrm{SnO}_{2}$ with other co-photocatalysts, including inorganic and organic semiconductors, is a practical approach to enhance the charge transfer efficacy for the photocatalytic process. The photocatalytic degradation of $\mathrm{NO}_{x}$ over $\mathrm{SnO}_{2}$ as a host photocatalyst is reported to be considerably enhanced after the combination with organic semiconductors such as graphitic carbon nitride $\left(\mathrm{g}-\mathrm{C}_{3} \mathrm{~N}_{4}\right)$ [71]. When acting as an auxiliary photocatalyst, $\mathrm{SnO}_{2}$ promotes the photocatalytic activity of the primary material $[38,70,75,76]$.
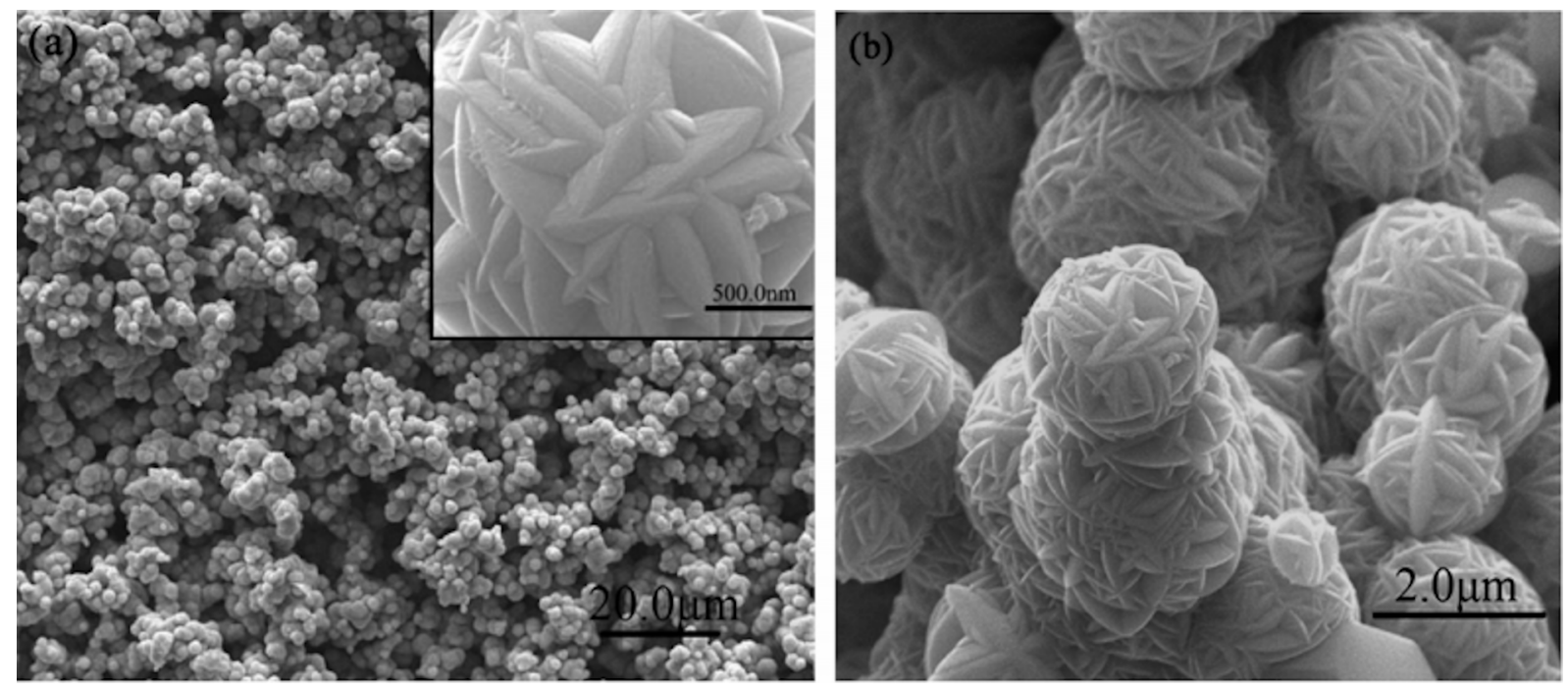

Figure 6: SEM images of $\mathrm{SnO}_{2}$ microspheres synthesized by a hydrothermal method at $180{ }^{\circ} \mathrm{C}$ for $24 \mathrm{~h}$. Figure 6 was reprinted with permission from [66], Copyright 2010 American Chemical Society. This content is not subject to CC BY 4.0. 

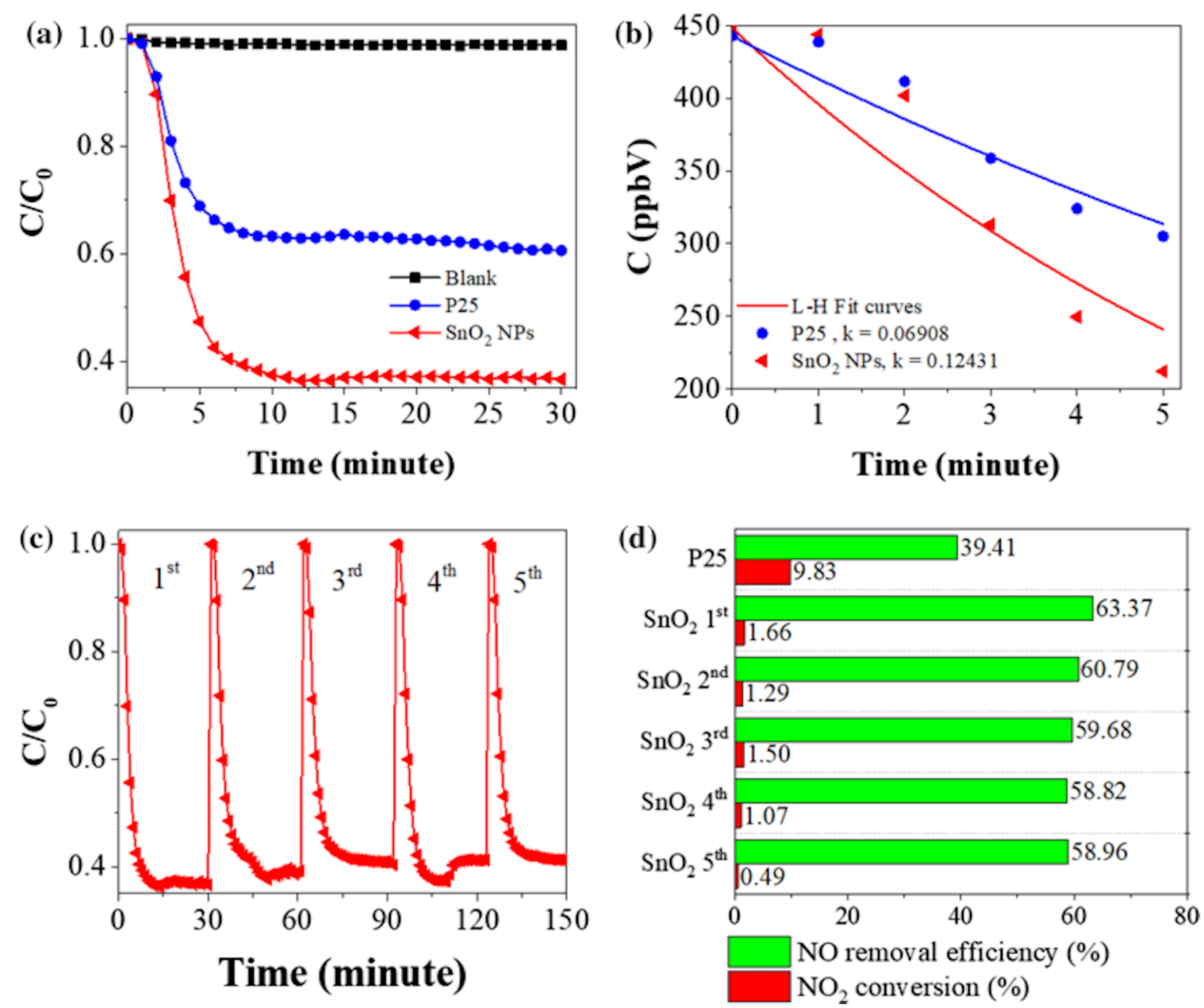

Figure 7: NO photodegradation of materials under solar light (a), the dependence of concentration on irradiation time (b), photochemical stability of $\mathrm{SnO}_{2} \mathrm{NPs}$ (NPs) (c), and $\mathrm{NO}$ removal efficacy and $\mathrm{NO}_{2}$ conversion efficacy (d). Figure 7 is from [69] and was reprinted by permission from Springer Nature from the journal Environmental Chemistry Letters ("High photocatalytic removal of NO gas over $\mathrm{SnO}_{2}$ nanoparticles under solar light" by $\mathrm{T}$. $\mathrm{H}$. Huy; B. D. Phat; C. M. Thi; P. V. Viet), Copyright 2018 Springer Nature. This content is not subject to CC BY 4.0.

\begin{tabular}{|c|c|c|c|c|c|c|c|c|c|}
\hline \multirow[t]{2}{*}{ Year } & \multirow[t]{2}{*}{ Photocatalyst } & \multirow{2}{*}{$\begin{array}{l}\mathrm{SnO}_{2} \\
\text { morphology }\end{array}$} & \multicolumn{4}{|c|}{ Experimental conditions } & \multirow{2}{*}{$\begin{array}{l}\text { NO removal } \\
(\%)\end{array}$} & \multirow[t]{2}{*}{$\mathrm{NO}_{2}$ yield (\%) } & \multirow[t]{2}{*}{ Ref. } \\
\hline & & & Light source & $\begin{array}{l}\text { Initial } \\
\text { NO } \\
\text { conc. } \\
\text { (ppb) }\end{array}$ & $\begin{array}{l}\text { Humidity } \\
(\%)\end{array}$ & $\begin{array}{l}\text { Sample } \\
\text { weight } \\
\text { (g) }\end{array}$ & & & \\
\hline 2013 & $\mathrm{SnO}_{2}$ & microspheres & $\begin{array}{l}\text { vis: } \lambda>510 \mathrm{~nm} \\
\text { and } \lambda>400 \mathrm{~nm} \text {; } \\
\text { UV: } \lambda>290 \mathrm{~nm} \\
(450 \mathrm{~W} \\
\text { high-pressure } \\
\text { mercury lamp with } \\
\text { filters) }\end{array}$ & $10^{3}$ & $\mathrm{~N} / \mathrm{A}$ & $\mathrm{N} / \mathrm{A}$ & $\begin{array}{l}57.2 \\
(\lambda>290 \mathrm{~nm}) \\
11.5 \\
(\lambda>400 \mathrm{~nm}) \\
4.2 \\
(\lambda>510 \mathrm{~nm})\end{array}$ & $\mathrm{N} / \mathrm{A}$ & {$[67]$} \\
\hline 2017 & $\begin{array}{l}\mathrm{SnO}_{2} / \mathrm{Zn}_{2} \mathrm{SnO}_{4} / \\
\text { graphene }\end{array}$ & unclear shape & $\begin{array}{l}\text { vis ( } 3 \mathrm{~W} \text { LED } \\
\text { lamp, } \\
\lambda=420 \pm 10 \mathrm{~nm})\end{array}$ & 600 & $\mathrm{~N} / \mathrm{A}$ & 0.2 & 59.3 & $\mathrm{~N} / \mathrm{A}$ & {$[75]$} \\
\hline
\end{tabular}




\begin{tabular}{|c|c|c|c|c|c|c|c|c|c|}
\hline 2018 & $\mathrm{SnO}_{2}$ & NPs & $\begin{array}{l}\text { solar ( } 300 \mathrm{~W} \text { Xe } \\
\text { lamp) }\end{array}$ & 450 & 70 & 0.2 & 63.37 & 1.66 & [69] \\
\hline 2018 & $\mathrm{SnO}_{2} / \mathrm{TiO}_{2}$ & NPs & $\begin{array}{l}\text { vis }(300 \mathrm{~W} \text { Xe } \\
\text { lamp with a UV } \\
\text { cutoff filter } \\
(\lambda>420 \mathrm{~nm})\end{array}$ & 450 & 70 & 0.2 & 59.49 & 2.58 & [38] \\
\hline 2018 & $\mathrm{SnO}_{2} /$ graphene & QDs & $\begin{array}{l}\text { solar and vis (Xe } \\
\text { lamp) }\end{array}$ & 600 & $\mathrm{~N} / \mathrm{A}$ & $\mathrm{N} / \mathrm{A}$ & $\begin{array}{l}75 \text { (full } \\
\text { spectrum) } \\
57 \text { (vis) }\end{array}$ & $N / A$ & [36] \\
\hline 2018 & $\mathrm{SnO}_{2} /$ polyaniline & NPs & $\begin{array}{l}\text { solar ( } 300 \text { W Xe } \\
\text { lamp) }\end{array}$ & 450 & 30 & 0.2 & 15 & 8 & [35] \\
\hline 2019 & $\begin{array}{l}\mathrm{SnO}_{2} / \mathrm{N} \text {-doped } \\
\text { carbon quantum } \\
\text { dots } / \mathrm{ZnSn}(\mathrm{OH})_{6}\end{array}$ & NPs & $\begin{array}{l}\text { vis-near-infrared } \\
(300 \mathrm{~W} \text { Xe lamp, } \\
\lambda \geq 420 \mathrm{~nm})\end{array}$ & 400 & $30 \pm 5$ & 0.2 & 37 & $<1.25$ & [76] \\
\hline 2019 & $\mathrm{SnO}_{2} / \mathrm{g}-\mathrm{C}_{3} \mathrm{~N}_{4}$ & QDs & $\begin{array}{l}\text { vis }(150 \mathrm{~W} \\
\text { tungsten halogen } \\
\text { lamp with a filter } \\
(\lambda>420 \mathrm{~nm})\end{array}$ & 600 & $\mathrm{~N} / \mathrm{A}$ & 0.4 & 32 & 8 & [37] \\
\hline 2019 & $\mathrm{Ag} @ \mathrm{SnO}_{2}$ & NPs & $\begin{array}{l}\text { solar ( } 300 \text { W Xe } \\
\text { lamp) }\end{array}$ & $N / A$ & $\mathrm{~N} / \mathrm{A}$ & 0.2 & 70 & 4 & [72] \\
\hline 2020 & Ce doped $\mathrm{SnO}_{2}$ & particles & $\begin{array}{l}\text { vis }(300 \mathrm{~W} \text { Xe } \\
\text { lamp with a UV } \\
\text { filter }(\lambda>420 \mathrm{~nm})\end{array}$ & $10^{4}$ & 65 & 0.4 & 82 & 10 & [39] \\
\hline 2020 & $\mathrm{BiOBr} / \mathrm{SnO}_{2}$ & NPs & $\begin{array}{l}\text { vis }(150 \mathrm{~W} \\
\text { tungsten halogen } \\
\text { lamp with a UV } \\
\text { cut-off filter } \\
(\lambda>420 \mathrm{~nm})\end{array}$ & 600 & $\mathrm{~N} / \mathrm{A}$ & 0.10 & 50.3 & $\begin{array}{l}\mathrm{N} / \mathrm{A} \\
\text { (NO-to-NO }{ }_{2} \\
\text { conversion was } \\
\text { studied via in } \\
\text { situ DRIFTS) }\end{array}$ & [70] \\
\hline 2021 & $\mathrm{~g}-\mathrm{C}_{3} \mathrm{~N}_{4} / \mathrm{SnO}_{2}$ & NPs & $\begin{array}{l}\text { vis }(300 \mathrm{~W} \text { solar } \\
\text { simulator with a } \\
\text { UV filter } \\
(\lambda>420 \mathrm{~nm})\end{array}$ & 500 & 70 & 0.2 & 44.17 & 9.29 & [71] \\
\hline 2021 & $\mathrm{SnO}_{2-x} / \mathrm{g}-\mathrm{C}_{3} \mathrm{~N}_{4}$ & NPs & $\begin{array}{l}\text { vis }(300 \mathrm{~W} \text { solar } \\
\text { simulator with a } \\
\text { UV cut-off filter } \\
(\lambda>420 \mathrm{~nm})\end{array}$ & 500 & $\mathrm{~N} / \mathrm{A}$ & 0.2 & 40.8 & 7.5 & [73] \\
\hline
\end{tabular}

$\mathrm{Wu}$ et al. reported the visible-light-driven elimination of $\mathrm{NO}$ over hydrothermally synthesized $\mathrm{BiOBr} / \mathrm{SnO}_{2} \mathrm{p}-\mathrm{n}$ heterojunction photocatalysts. The as-prepared $\mathrm{BiOBr} / \mathrm{SnO}_{2}$ photocatalayst with a molar ratio of 2:5 between $\mathrm{SnO}_{2}$ NPs and $\mathrm{BiOBr}$ microspheres shows an enhanced $\mathrm{NO}_{x}$ photocatalytic removal of $50.3 \%$, at an initial NO concentration of $600 \mathrm{ppb}$, and a great stability after four cycles. The generation of toxic $\mathrm{NO}_{2}$ products was inhibited effectively. The charge movement at the $\mathrm{BiOBr} / \mathrm{SnO}_{2} \mathrm{p}-\mathrm{n}$ interface was also revealed via theoretical and experimental findings. Electrons in $\mathrm{SnO}_{2}$ transfer into $\mathrm{BiOBr}$ over pre-formed charge migration channels and an internal electric field at the $\mathrm{BiOBr} / \mathrm{SnO}_{2}$ interface, which directs photoinduced electrons from the $\mathrm{CB}$ of $\mathrm{BiOBr}$ to that of $\mathrm{SnO}_{2}$, thus prolonging the lifetime of photogenerated electron-hole pairs (Figure 8). The NO-to- $\mathrm{NO}_{2}$ conversion and intermediates and products were confirmed via in situ diffuse reflectance infrared Fourier transform spectroscopy during NO oxidation [70].
Huy et al. [38] hydrothermally synthesized $\mathrm{SnO}_{2}$ NPs adhering to $\mathrm{TiO}_{2}$ nanotubes $\left(\mathrm{SnO}_{2} / \mathrm{TNTs}\right)$ via a facile one-step method for the photocatalytic abatement of NO under visible light (Figure 9). At a NO concentration of $450 \mathrm{ppb}$ in a continuous flow, $\mathrm{SnO}_{2}$ /TNTs yields a photocatalytic degradation of NO of $59.49 \%$, which is much better than that of bare $\mathrm{TiO}_{2} \mathrm{NTs}$ (44.61\%), $\mathrm{SnO}_{2} \mathrm{NPs}(39.55 \%)$, and a physical blend of $\mathrm{SnO}_{2}$ NPs and $\mathrm{TiO}_{2}$ NTs (39.18\%). Also, the heterostructured photocatalyst shows an effective reduction of $\mathrm{NO}_{2}$ generation after $30 \mathrm{~min}$ of photocatalytic reaction. The photogenerated electrons and ${ }^{\circ} \mathrm{O}_{2}{ }^{-}$radicals played a primary role in the photocatalytic NO oxidation. Additionally, using photoluminescence (PL) spectroscopy, XPS, active species trapping tests, and ESR spectroscopy, the authors studied the photoinduced charge migration and trapping. They proposed the band structure of the $\mathrm{SnO}_{2} / \mathrm{TNT}$ and pointed out the existence of ${ }^{\bullet} \mathrm{O}_{2}{ }^{-}$and ${ }^{\bullet} \mathrm{OH}$ radicals as critical factors in the photocatalysis process [38]. These results demonstrated that the $\mathrm{SnO}_{2}$ NPs could be both a host or an auxiliary material for the NO photocatalytic degradation. 


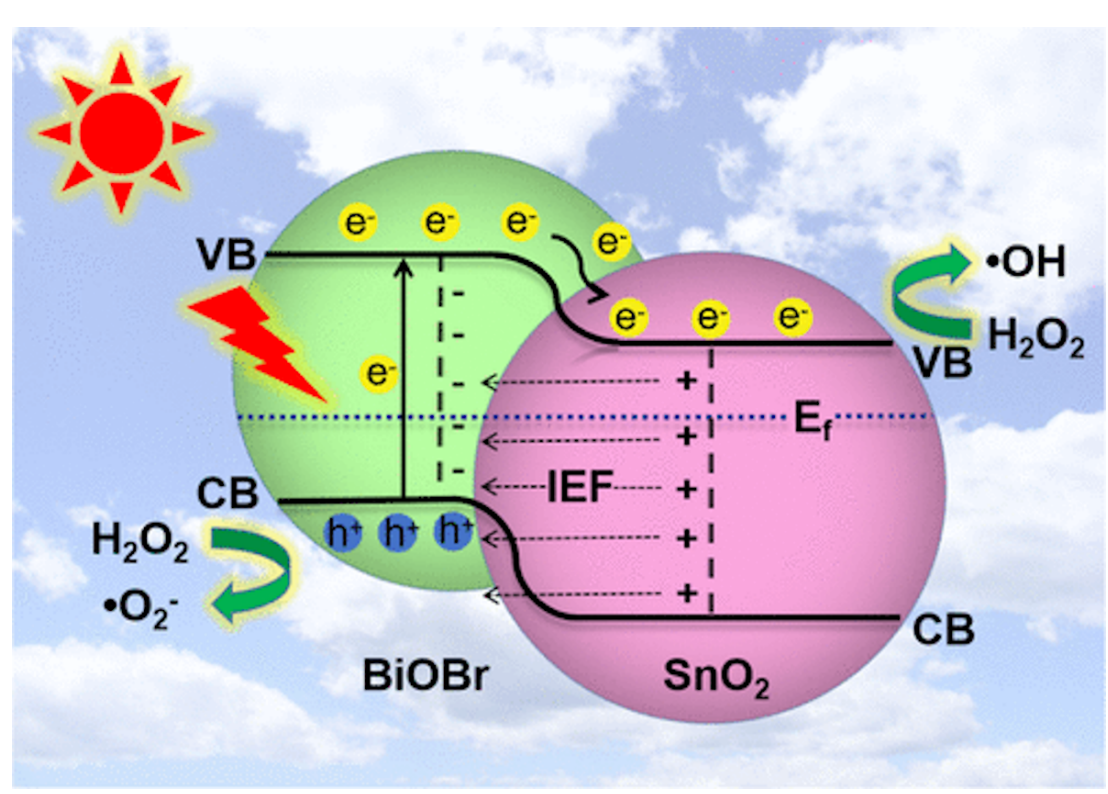

Figure 8: Proposed mechanisms for photocatalytic $\mathrm{NO}$ oxidation via interfacial charge migration over $\mathrm{BiOBr} / \mathrm{SnO} \mathrm{O}_{2} \mathrm{p}-\mathrm{n}$ heterojunctions. Figure 8 was reprinted with permission from [70], Copyright 2020 American Chemical Society. This content is not subject to CC BY 4.0.

(a)

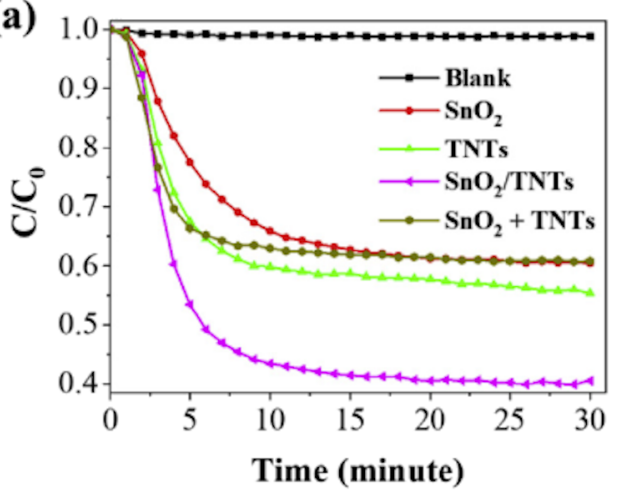

(c)

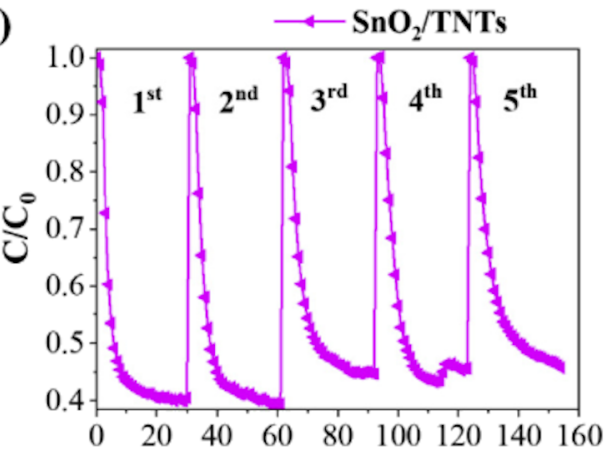

(b)

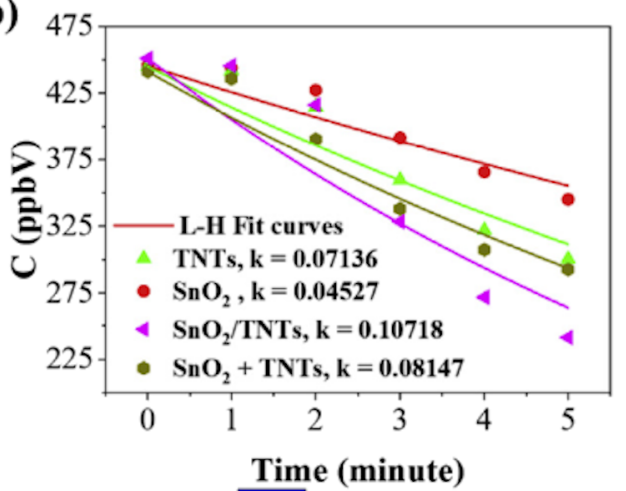

(d)

$$
\mathrm{NO}_{2} \text { conversion (\%) }
$$

NO removal efficiency $(\%)$

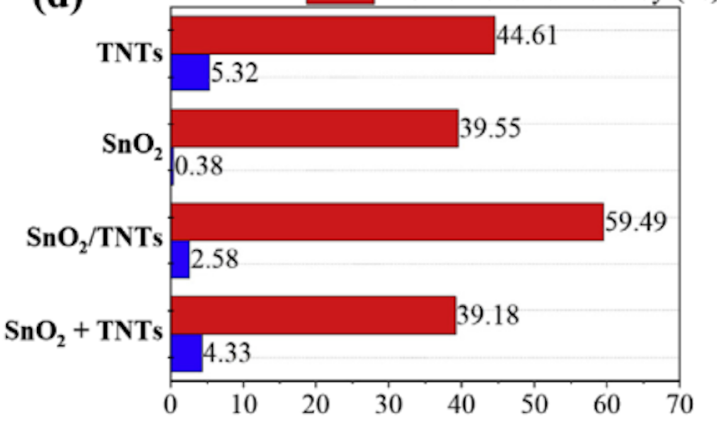

Time (minute)

Figure 9: NO photocatalytic degradation of materials under visible light irradiation (a), the dependence of concentration on irradiation time (b), photochemical stability of $\mathrm{SnO}_{2}$ /TNTs (c), and NO removal efficacy and $\mathrm{NO}_{2}$ conversion efficacy (d). Figure 9 was reprinted from [38], Chemosphere, vol. 215, by Huy, T. H.; Bui, D. P.; Kang, F.; Wang, Y. F.; Liu, S. H.; Thi, C. M.; You, S. J.; Chang, G. M.; Pham, V. V. "SnO $2 / \mathrm{TiO}_{2}$ nanotube heterojunction: The first investigation of NO degradation by visible-light-driven photocatalysis", pages 323-332, Copyright (2018), with permission from Elsevier. This content is not subject to CC BY 4.0. 
Besides the coupling with semiconductor oxides such as $\mathrm{TiO}_{2}$ and $\mathrm{BiOBr}$, recent works reported the successful combination of $\mathrm{SnO}_{2}$ nanomaterials with conjugated polymers such as graphitic carbon nitride $\left(\mathrm{g}-\mathrm{C}_{3} \mathrm{~N}_{4}\right)$ and polyaniline (PANI), yielding metal-free visible-light-driven photocatalysts for addressing $\mathrm{NO}$ gas pollution. Such combinations hold great potential because they exhibit a wide range of useful properties, including high conductivity, cost-effectiveness, high flexibility and processability, and ease of fabrication. These recent advances are highlighted and discussed in terms of preparation method and photocatalytic mechanism in this review. Regarding g- $_{3} \mathrm{~N}_{4}$, Zou et al. successfully deposited $\mathrm{SnO}_{2}$ quantum dots (QDs) on g- $\mathrm{C}_{3} \mathrm{~N}_{4}$ sheets by a simple physical mixing process. The authors indicated that the $\mathrm{SnO}_{2} / \mathrm{g}-\mathrm{C}_{3} \mathrm{~N}_{4}$ photocatalyst had a twice as high $\mathrm{NO}$ removal efficacy than bare $\mathrm{SnO}_{2}$ QDs and a low $\mathrm{NO}_{2}$ generation upon exposure to visible light for $30 \mathrm{~min}$. This enhance- ment of the photocatalytic activity was interpreted as the synergistic effect between the high photo-oxidation ability of $\mathrm{SnO}_{2}$ triggered by the visible light response of $\mathrm{g}-\mathrm{C}_{3} \mathrm{~N}_{4}$. Also, the key role of the $\mathrm{SnO}_{2} / \mathrm{g}-\mathrm{C}_{3} \mathrm{~N}_{4}$ interface in inhibiting the production of $\mathrm{NO}_{2}$ facilitates the transition of photogenerated carriers used for the NO removal [37].

Pham et al. showcased a step-scheme (S-scheme) photocatalyst composed of 2D/0D g- $\mathrm{C}_{3} \mathrm{~N}_{4}$ nanosheet-assisted $\mathrm{SnO}_{2} \mathrm{NPs}$ $\left(\mathrm{g}-\mathrm{C}_{3} \mathrm{~N}_{4} / \mathrm{SnO}_{2}\right.$ ) for removing $\mathrm{NO}$ with low $\mathrm{NO}_{2}$ generation. This work established an S-scheme charge transfer path by combining density functional theory (DFT) calculations, trapping experiments, and electron spin resonance measurements (Figure 10). Thus, the impact of intrinsic OVs within $\mathrm{SnO}_{2} \mathrm{NPs}$ and the resulting $\mathrm{S}$-scheme heterojunction on the band structure, charge transfer, and photocatalytic activity was presented. The

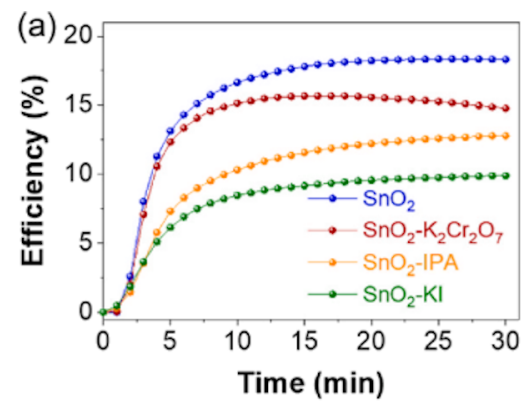

(d)

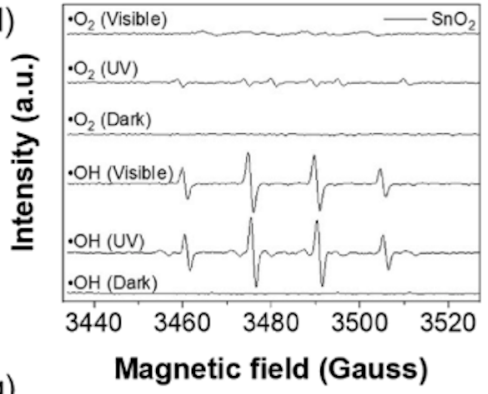

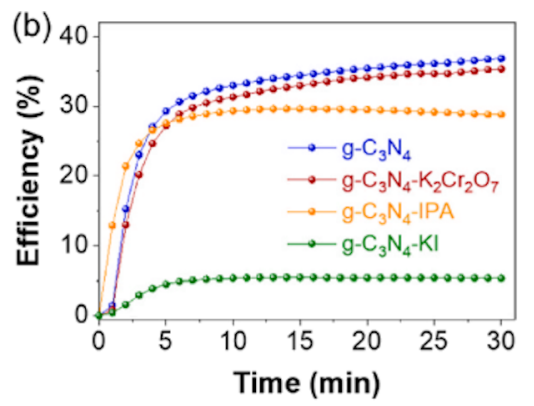

(e)

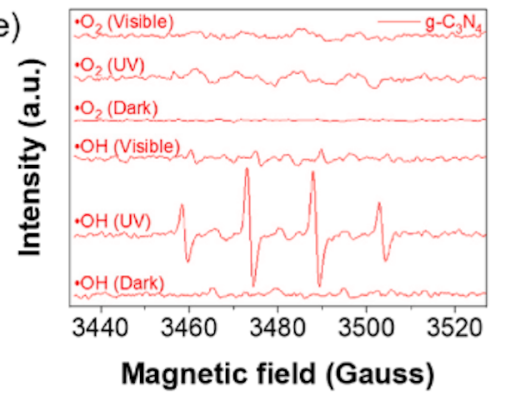

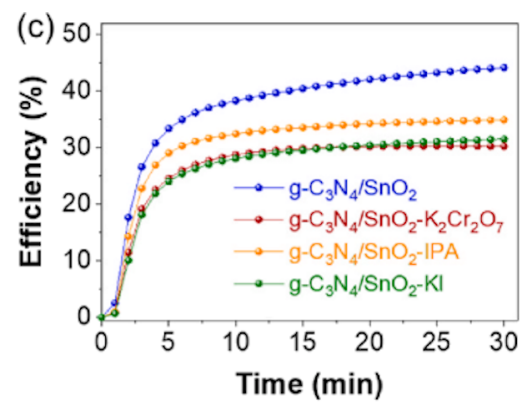

(f)
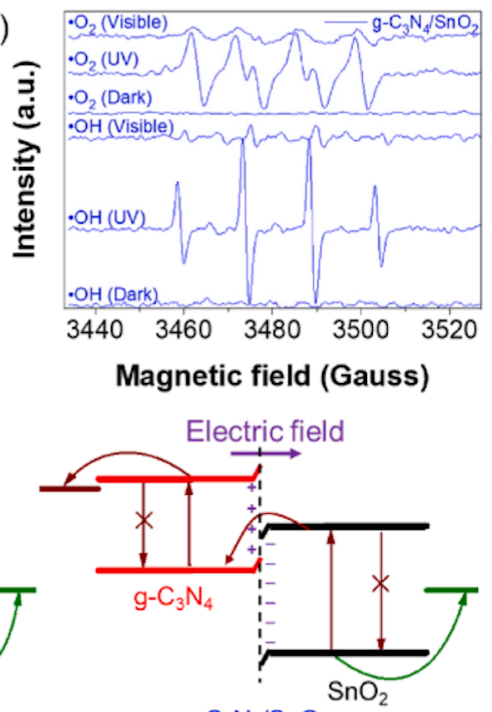

$\mathrm{g}-\mathrm{C}_{3} \mathrm{~N}_{4} / \mathrm{SnO}_{2}$
Before contact

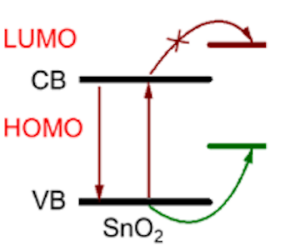

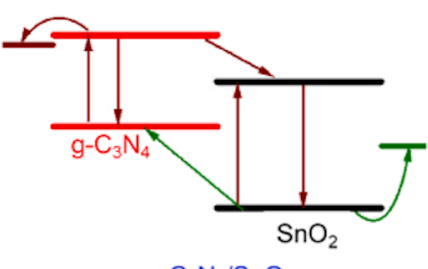

$\mathrm{g}-\mathrm{C}_{3} \mathrm{~N}_{4} / \mathrm{SnO}_{2}$

(Type II heterojunction mechanism)

Figure 10: Photocatalytic NO removal efficacy over $\mathrm{SnO}_{2}$ (a), g- $\mathrm{C}_{3} \mathrm{~N}_{4}$ (b) and $\mathrm{g}-\mathrm{C}_{3} \mathrm{~N}_{4} / \mathrm{SnO} \mathrm{O}_{2}$ (c) with scavengers under visible light (400< $\lambda<800$ ). ESR signals (d) of ${ }^{\circ} \mathrm{OH}$ radicals, and ${ }^{\circ} \mathrm{O}_{2}{ }^{-}$radicals of the materials after 10 min under visible light $(400<\lambda<800)$. Growth curves of ${ }^{\circ} \mathrm{OH}$ radicals (e) and ${ }^{\circ} \mathrm{O}_{2}{ }^{-}$radicals (f) vs irradiation time of the materials. The charge transfer pathways of the materials $(\mathrm{g})$. $\mathrm{K}_{2} \mathrm{Cr}_{2} \mathrm{O}_{7}, \mathrm{KI}$, and isopropyl alcohol (IPA) act as scavengers for electrons, holes, and ${ }^{\circ} \mathrm{OH}$ radicals, respectively. The brown and green arrows indicate the path of electrons and holes, respectively. Figure 10 was reprinted from [71], Environmental Pollution, vol. 286, by Van Pham, V.; Mai, D.-Q.; Bui, D.-P.; Van Man, T.; Zhu, B.; Zhang, L.; Sangkaworn, J.; Tantirungrotechai, J.; Reutrakul, V.; Cao, T. M. "Emerging 2D/0D g-C3N4/SnO2 S-scheme photocatalyst: New generation architectural structure of heterojunctions toward visible-light-driven NO degradation", article no. 117510, Copyright (2021), with permission from Elsevier. This content is not subject to CC BY 4.0 . 
resulting heterojunction photocatalytically removed $40 \% \mathrm{NO}$ (initial concentration of $500 \mathrm{ppb}$ ) and showed excellent photostability under visible light. The $\mathrm{NO}_{2}$ production from the photocatalytic reaction was also negligible. The good photocatalytic $\mathrm{NO}$ degradation of the $2 \mathrm{D} / 0 \mathrm{D} \mathrm{g}-\mathrm{C}_{3} \mathrm{~N}_{4} / \mathrm{SnO}_{2}$ catalyst is due to the defects actively trapping electrons and the charge transfer described in the S-scheme model. These factors increase the lifetime of electron-hole pairs and free radicals. The finding of this work enables the generation of a new and innovative structures with S-scheme heterojunctions for environmental treatment [71].

A similar model, a Z-scheme photocatalyst, was reported by $\mathrm{Lu}$ et al. who successfully fabricated a ternary nanohybrid consisting of mesoporous $\mathrm{SnO}_{2}$, nitrogen-doped carbon quantum dots (NCDs), and $\mathrm{ZnSn}(\mathrm{OH})_{6}$ using a simple in situ solvothermal method. This nanohybrid photocatalyst exhibited a broad optical response range and excellent oxidation ability and showed great potential in addressing air pollution. The ternary Z-scheme photocatalyst could remove $37 \%$ of NO under visible light and IR without generating $\mathrm{NO}_{2}$. In addition, this work also discussed the critical role of NCDs in extending the light harvesting range and promoting the separation of photogenerated electrons. A considerable amount of reactive oxygen radicals was produced during the photocatalytic reaction, resulting from the large amount of free surface $\mathrm{OH}$ groups. PL, photocurrent response, electrochemical impedance spectroscopy (EIS) data, and the nanosecond-level time-resolved fluorescence decay spectra (Figure 11) demonstrated that the $\mathrm{SnO}_{2} / \mathrm{NCDs} /$ ZHS nanohybrid achieved low charge carrier recombination, high photoactivity, and excellent photoinduced charge transfer to the surface of the semiconductor. This study enables new insights into the underlying mechanism of heterojunction photocatalysts, especially those with Z-shaped interfaces [76].
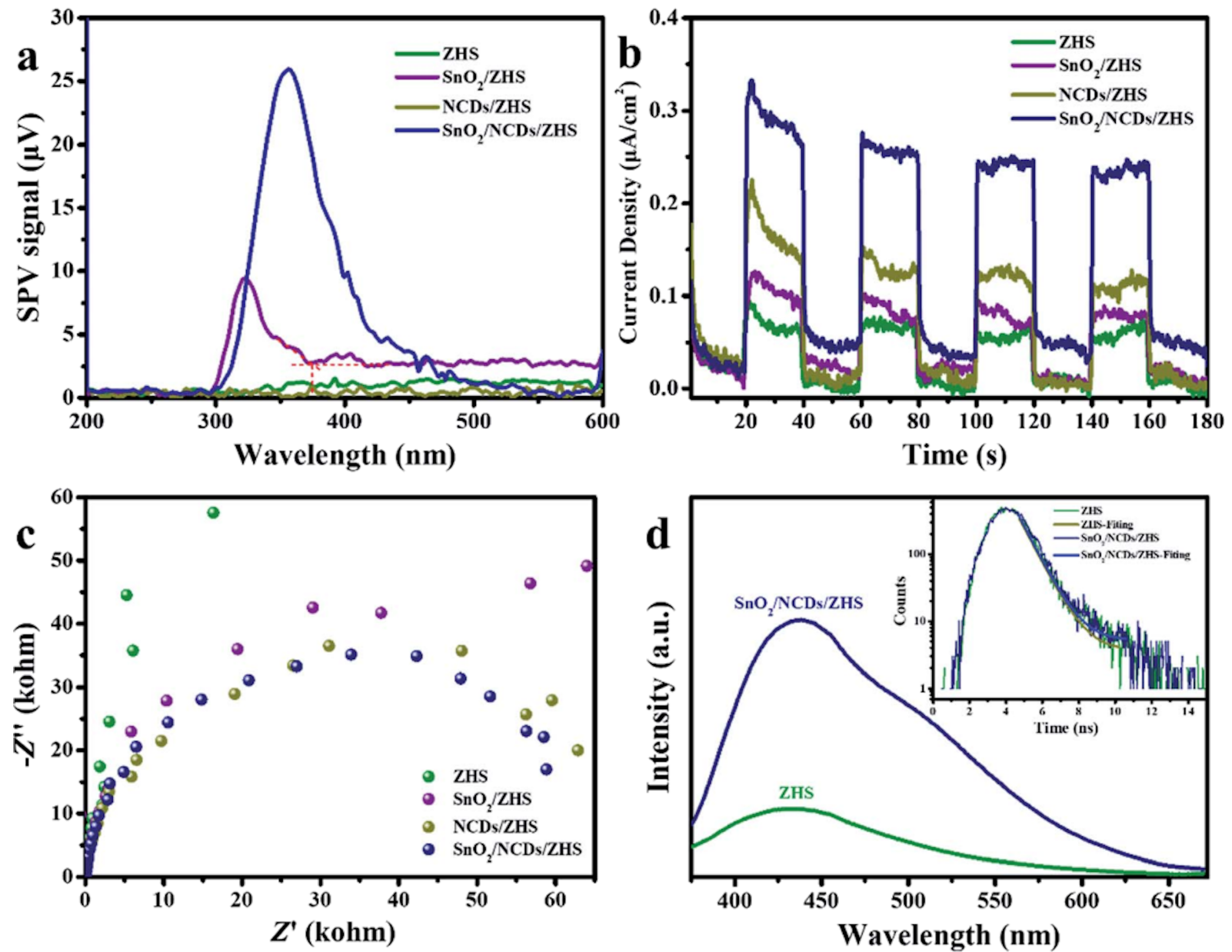

Figure 11: (a) Surface photovoltage spectroscopy, (b) transient photocurrent responses, (c) EIS Nyquist plots of $\mathrm{ZHS}, \mathrm{SnO}_{2} / \mathrm{ZHS}, \mathrm{NCDs} \mathrm{ZHS}$ and $\mathrm{SnO}_{2} / \mathrm{NCDs} / \mathrm{ZHS}$ samples, and (d) PL spectra (inset: transient fluorescence decay spectra). Figure 11 was republished with permission of The Royal Society of Chemistry from [76] ("Constructing Z-scheme $\mathrm{SnO}_{2} / \mathrm{N}$-doped carbon quantum dots/ZnSn $(\mathrm{OH})_{6}$ nanohybrids with high redox ability for $\mathrm{NO}{ }_{x}$ removal under VIS-NIR light" by Y. Lu et al., J. Mater. Chem. A, vol. 7, issue 26, () 2019); permission conveyed through Copyright Clearance Center, Inc. This content is not subject to CC BY 4.0 . 
Polyaniline (PANI) is a conducting polymer and compared to g- $\mathrm{C}_{3} \mathrm{~N}_{4}$, PANI is inexpensive and easy to synthesize. Bui et al. [35] presented a $\mathrm{SnO}_{2} / \mathrm{PANI}$ nanocomposite for photocatalytic NO removal under solar light for the first time. Furthermore, they found that the introduction of $\mathrm{SnO}_{2}$ NPs increases the photostability of PANI during the photocatalytic process, which holds great potential for scalable manufacturing. Also, this work thoroughly discussed the adsorption and photocatalytic mechanisms, and the polymer photodegradation of the resulting nanocomposite using DFT techniques. The results confirmed that the interaction between NO and PANI is indeed a hydrogen bond and photogenerated holes serve as the primary factor of the photocatalytic NO removal [35]. Moreover, this study also indicated that hydrogen bonds between NO and PANI increased the adsorption of $\mathrm{NO}$ on the $\mathrm{SnO}_{2} / \mathrm{PANI}$ surface, leading to enhanced photocatalysis. However, the photocatalytic stability of $\mathrm{SnO}_{2} / \mathrm{PANI}$ is still a challenging problem.

Enesca et al. [29] developed photoactive heterostructures based on $\mathrm{SnO}_{2}, \mathrm{TiO}_{2}$, and $\mathrm{CuInS}_{2}$ using an automated spray pyrolysis method, which is particularly beneficial for air cleaning applications. This work showed that the surface tension of the material surface directly impacts the photocatalytic activity under humid conditions. Furthermore, introducing $\mathrm{CuInS}_{2}$ enables good UV and vis absorption thus extending the light-responsive range. As a result, such a $\mathrm{CuInS} / 2 / \mathrm{TiO}_{2} / \mathrm{SnO}_{2}$ heterostructure presented one of the highest photocatalytic efficacies $(51.7 \%)$ in acetaldehyde removal. However, this work also opens some new questions for future studies on optimizing the band structure, which remains critical for studying charge separation [29]. In another study, a $\mathrm{SnO}_{2}-\mathrm{Zn}_{2} \mathrm{SnO}_{4} \mathrm{Z}$-scheme photocatalyst system was prepared with a graphene modification to create surface vacancy sites in the composite, which contributed to an enhanced photoactivity in the oxidation of NO and acetone [75]. The presence of graphene induces the formation of $\mathrm{SnO}_{2}$ and introduces $\mathrm{Sn}$ vacancies, which supports the electron transfer from the $\mathrm{CB}$ of $\mathrm{Zn}_{2} \mathrm{SnO}_{4}$ to oxygen under visible light irradiation (Figure 12). The authors only used a visible light LED with low power ( $3 \mathrm{~W}$ ) and obtained a high efficacy of NO degradation $(59.3 \%)$ [75]. However, the disadvantage of this study and other studies is that it did not determine the formation of $\mathrm{NO}_{2}$ after the reaction (see Table 1).

\section{Creation of narrower bandgaps}

To narrow the bandgap of $\mathrm{SnO}_{2}$ is an advanced strategy for enhancing photocatalytic ability. Specifically, reducing the bandgap of $\mathrm{SnO}_{2}$ will increase the photoresponse in the visible light region, making up $45 \%$ of the solar spectrum. Moreover, reducing the bandgap will also create many defect states that can decrease the recombination of photogenerated electron-hole

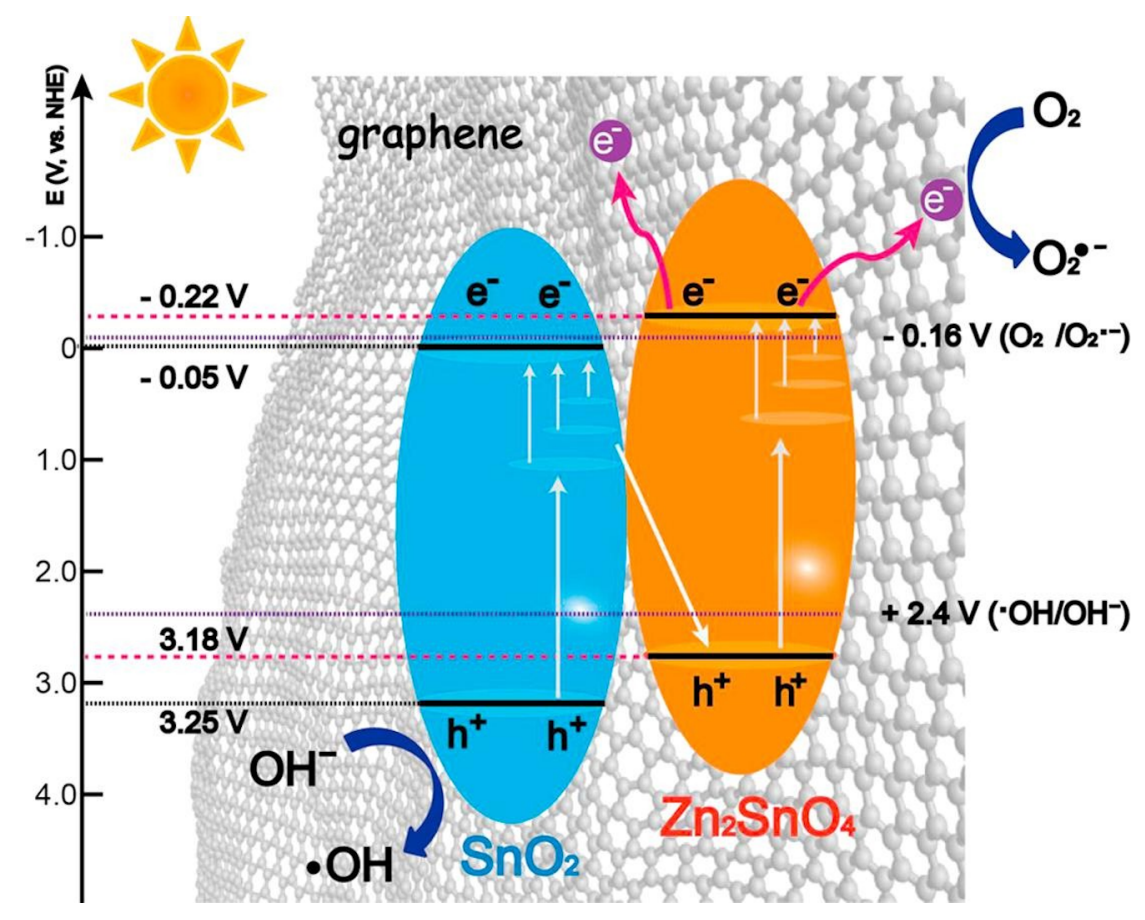

Figure 12: A mechanism of $\mathrm{NO}$ photocatalytic oxidation over $\mathrm{SnO}_{2}-\mathrm{Zn}_{2} \mathrm{SnO}_{4} /$ graphene. Figure 12 was reprinted from [75], Chemical Engineering Journal, vol. 336, by Li, Y.; Wu, X.; Ho, W.; Lv, K.; Li, Q.; Li, M.; Lee, S. C. "Graphene-induced formation of visible-light-responsive SnO ${ }_{2}-\mathrm{Zn}_{2} \mathrm{SnO}_{4}$ Z-scheme photocatalyst with surface vacancy for the enhanced photoreactivity towards NO and acetone oxidation", pages 200-210, Copyright (2017), with permission from Elsevier. This content is not subject to CC BY 4.0. 
pairs. There are many approaches to narrowing the bandgap of $\mathrm{SnO}_{2}$, such as modifying $\mathrm{SnO}_{2}$ by noble metal, graphene, or doping, including self-doping $\mathrm{SnO}_{2}\left(\mathrm{Sn}^{2+}\right.$-doped $\mathrm{SnO}_{2}$ or $\mathrm{SnO}_{2-x}$ ). In general, doping $\mathrm{SnO}_{2}$ will reduce the bandgap, which enhances the photoactivity in the visible light region for $\mathrm{SnO}_{2}$. The narrowing of the bandgap by introducing defects in metal oxide semiconductors opens up the possibility of their use in the visible spectrum [77]. Recently, Xie et al. reported using $\mathrm{SnO}_{2}$ /graphene quantum dot (GQD) composites. They showed that the absorption edge of as-prepared $\mathrm{SnO}_{2}$ (Figure 13a black line) is around $340 \mathrm{~nm}$, equaling to a bandgap of $3.64 \mathrm{eV}$. The PL peak of $\mathrm{SnO}_{2}$ was located in the range of $280-485 \mathrm{~nm}$ (Figure 13b). The combination of GQDs and $\mathrm{SnO}_{2}$ did not affect the shape of the PL peak. However, the corresponding PL intensity of the $\mathrm{SnO}_{2}$ /GQDs sample was decreased because of the greatly reduced radiative charge recombination of $\mathrm{SnO}_{2}$.
Moreover, enhanced visible light response and enhanced charge separation in the sample with GQDs have been observed (Figure 13c). The EIS measurements (Figure 13d) indicated that the diameter of the arc radius of $\mathrm{SnO}_{2}$ /GQDs (1\%) is much smaller than that of $\mathrm{SnO}_{2}$, confirming that the GQDs contributed to improving the charge separation, significantly reducing indoor NO under visible light irradiation. The optimized composite removed $57 \%$ of the initial NO while generating a negligible amount of $\mathrm{NO}_{2}$. In addition, this work found that the insertion of graphene quantum dots did not induce any noticeable impact on the structure of the $\mathrm{SnO}_{2}$ component. Still, its presence strongly enhanced energy harvesting and charge separation in the resulting composite [36].

Regarding the self-doping $\mathrm{SnO}_{2}$, Pham et al. reported on the fabrication of a $\mathrm{SnO}_{2-x} / \mathrm{g}-\mathrm{C}_{3} \mathrm{~N}_{4}$ heterojunction, inducing an
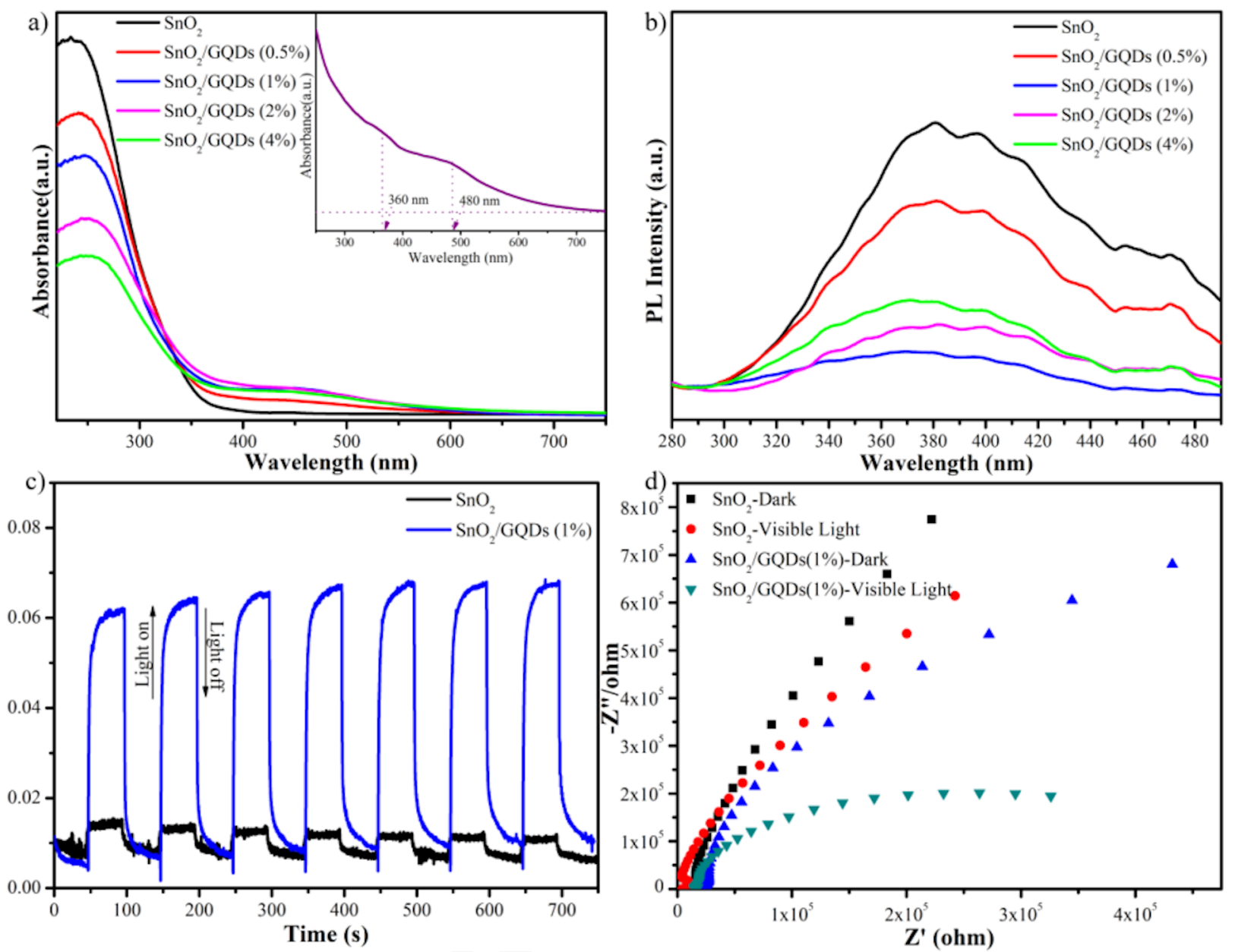

Figure 13: (a) Diffuse reflectance spectra of $\mathrm{SnO}_{2}$ and $\mathrm{SnO}_{2} / \mathrm{GQDs}$ composites. Inset is the absorption spectrum of GQDs dispersed in water. (b) PL spectra of $\mathrm{SnO}_{2}$ and $\mathrm{SnO}_{2} / \mathrm{GQDs}$ composites. Excitation wavelength: $260 \mathrm{~nm}$. (c) Transient photocurrent response and (d) EIS curves of SnO 2 and $\mathrm{SnO}_{2} / \mathrm{GQDs}(1 \%)$ under visible light illumination and in darkness. Figure 13 was reprinted from [36], Applied Surface Science, vol. 448, by Xie, Y.; Yu, S.; Zhong, Y.; Zhang, Q.; Zhou, Y. "SnO $\mathrm{S}_{2}$ graphene quantum dots composited photocatalyst for efficient nitric oxide oxidation under visible light", pages 655-661, Copyright (2018), with permission from Elsevier. This content is not subject to CC BY 4.0. 
S-scheme interface, showing impressive photocatalytic NO removal under visible light. In this work, Pham et al. indicated that deep trap centers of OV defects (Figure 14) formed with a very high concentration $\left(36.69 \%\right.$ ), mainly from $\mathrm{V}_{\mathrm{O}}$. and $\mathrm{V}_{\mathrm{O}}$. centers. These OVs reduced the bandgaps of $\mathrm{SnO}_{2}(3.7 \mathrm{eV})$ and $\mathrm{SnO}_{2-x}(3.17 \mathrm{eV})$, significantly impacting the reaction rate during the photocatalytic process, leading to enhanced NO removal under visible light. Also, the reported selectivity of the $\mathrm{SnO}_{2-x} / \mathrm{g}-\mathrm{C}_{3} \mathrm{~N}_{4}$ heterojunction is three times higher than that of the bare materials. The finding of this work further supports the importance of OVs in the design of photocatalytic materials [73].

Song et al. synthesized Ce-doped $\mathrm{SnO}_{2}$ materials with a high number of OVs to improve NO oxidation removal efficacy (Figure 15). The results showed that the excellent NO oxidation activity of $\mathrm{Ce}-\mathrm{SnO}_{2}$ materials was based on the OVs, which create a suitable site for the formation of $\mathrm{NO}^{-}$intermediates to generate nitrite and nitrate products in the photocatalytic reaction processes. Moreover, additional OVs could be readily formed by thermal treatment under argon atmosphere. The work suggested an innovative approach for developing high-performance photocatalysts and a cost-effective, environmentally benign way through heat treatment in different atmospheres [39].

Combining noble metals with $\mathrm{SnO}_{2}$, such as in $\mathrm{Au} / \mathrm{SnO}_{2}$ [78] or $\mathrm{Pd} / \mathrm{SnO}_{2}$ [79], is an advanced approach yielding an effective performance for gas sensing. However, There is only one report by Bui et al. on using $\mathrm{Ag} @ \mathrm{SnO}_{2} \mathrm{NPs}$ for removing NO, taking advantage of plasmonic-induced photocatalysis [72]. The $\mathrm{Ag} @ \mathrm{SnO}_{2} \mathrm{NPs}$ were fabricated by a simple and green approach using hydrothermal growth and photoreduction deposition. The introduction of Ag induced a bending of the band structure of $\mathrm{SnO}_{2} \mathrm{NPs}$, leading to a change of the Fermi level. As a result, the $\mathrm{Ag} @ \mathrm{SnO}_{2} \mathrm{NPs}$ showed an impressive photocatalytic NO removal of $70 \%$ while generating very little $\mathrm{NO}_{2}$ (4\%) after $30 \mathrm{~min}$. In addition, this work one to understand the
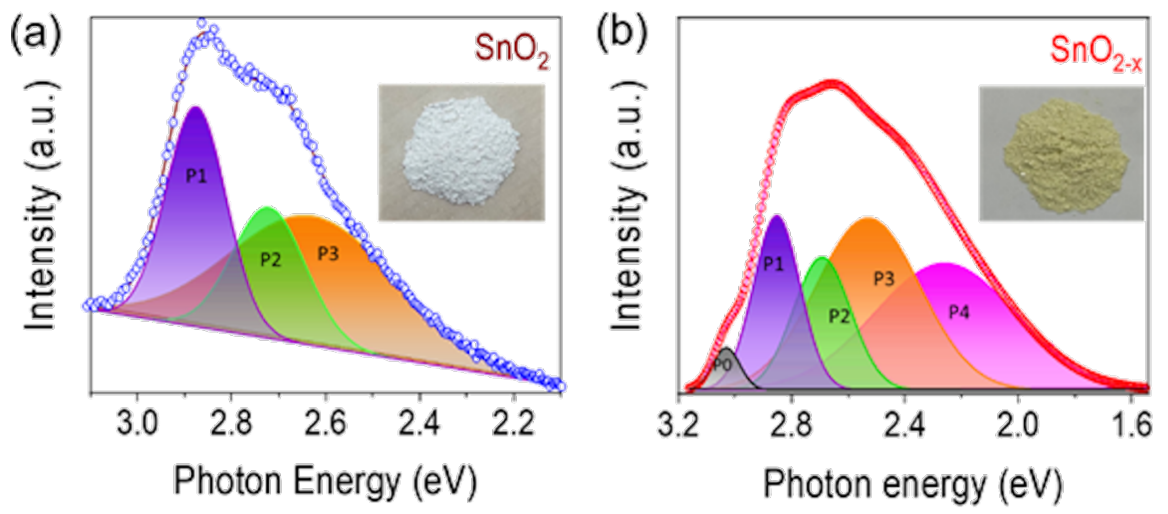

(c)

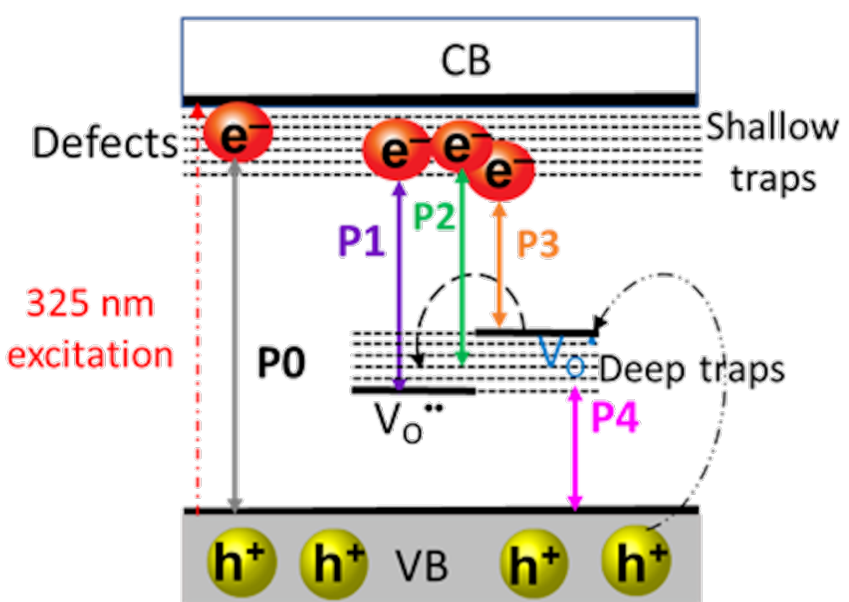

Figure 14: Gaussian fit of PL spectra with inserted images of sample color of $\mathrm{SnO}_{2}$ (a) and $\mathrm{SnO}_{2-x}$ (b); and proposed schematic model for emissions from defects in $\mathrm{SnO}_{2}$ and $\mathrm{SnO}_{2-x}$ (c). Figure 14 was reproduced from [73], @ 2021 The Chinese Ceramic Society. Production and hosting by Elsevier B.V. This is an open access article under the CC BY-NC-ND license (http://creativecommons.org/licenses/by-nc-nd/4.0/). This content is not subject to CC BY 4.0. 


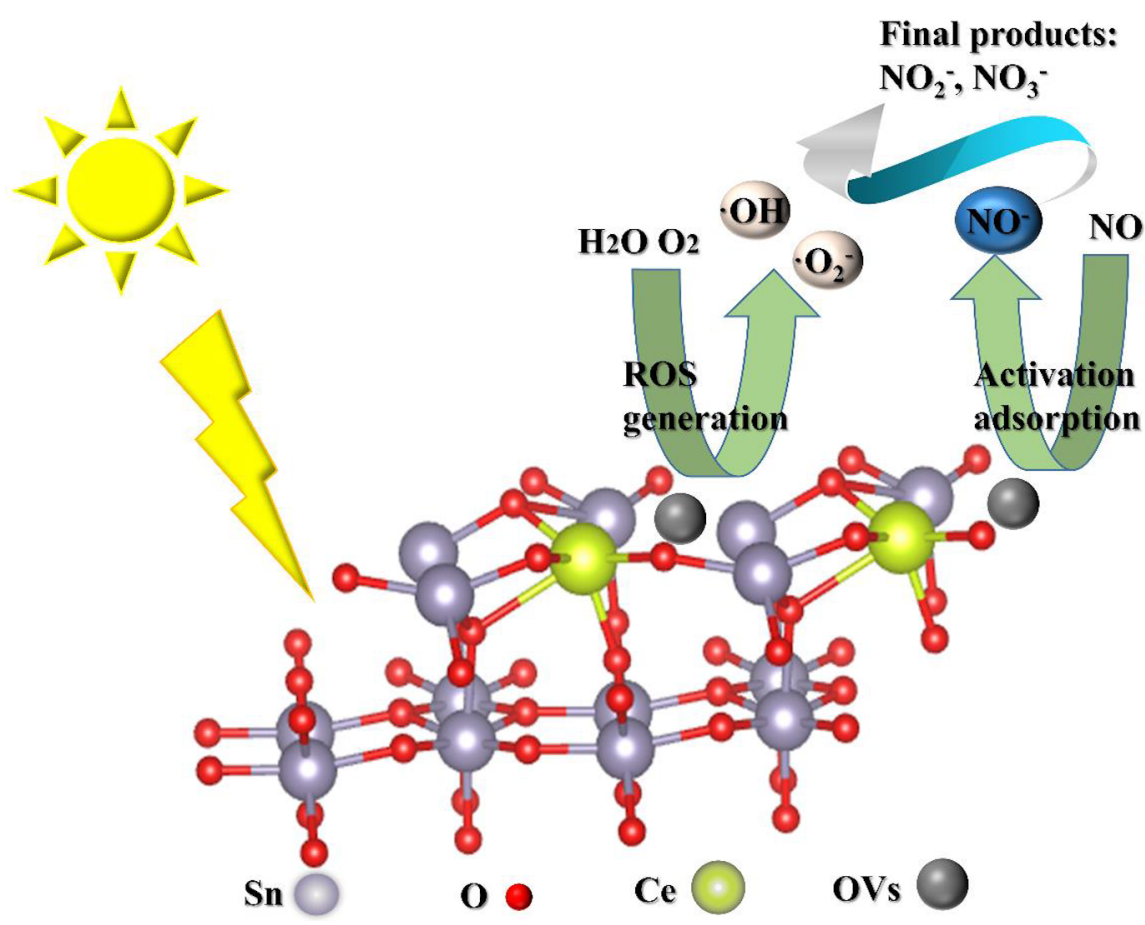

Figure 15: The proposed process of $\mathrm{NO}+\mathrm{O}_{2}$ reaction over $\mathrm{Ce}-\mathrm{SnO}_{2}$ under visible light irradiation. The $\mathrm{ROS}$ reacted with the activated $\mathrm{NO}-$ intermediates to nitrates and nitrites. Figure 15 was reprinted from [39], Applied Catalysis B: Environmental, vol. 284, by Song, X.; Qin, G.; Cheng, G.; Jiang,

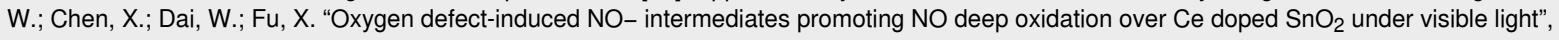
article no. 119761, Copyright (2020), with permission from Elsevier. This content is not subject to CC BY 4.0.

underlying photocatalytic mechanism through the species lifespan obtained from trapping experiments and time-dependent ESR signals (Figure 16). Electrons and holes are equally important for photocatalysis [72].

\section{Conclusion}

Regarding the improvement of the photocatalytic NO degradation over $\mathrm{SnO}_{2}$ nanomaterials there are many developments and approaches, such as $\mathrm{BiOBr} / \mathrm{SnO}_{2}, \mathrm{~g}-\mathrm{C}_{3} \mathrm{~N}_{4} / \mathrm{SnO}_{2}, \mathrm{SnO}_{2} / \mathrm{NCDs} /$ $\mathrm{ZnSn}(\mathrm{OH})_{6}$, Ce-doped $\mathrm{SnO}_{2}, \mathrm{SnO}_{2}$ self-doped with $\mathrm{Sn}^{2+}$, and $\mathrm{Ag} @ \mathrm{SnO}_{2}$. These systems yielded an enhanced photocatalytic $\mathrm{NO}_{x}$ degradation either through increasing the charge transfer, through structural changes leading to bandgap reduction, or through the generation of favorable surface states for the $\mathrm{NO}_{x}$ decomposition reaction. However, the performance in $\mathrm{NO}$ removal is still low (only nearly $60 \%$ under visible light and
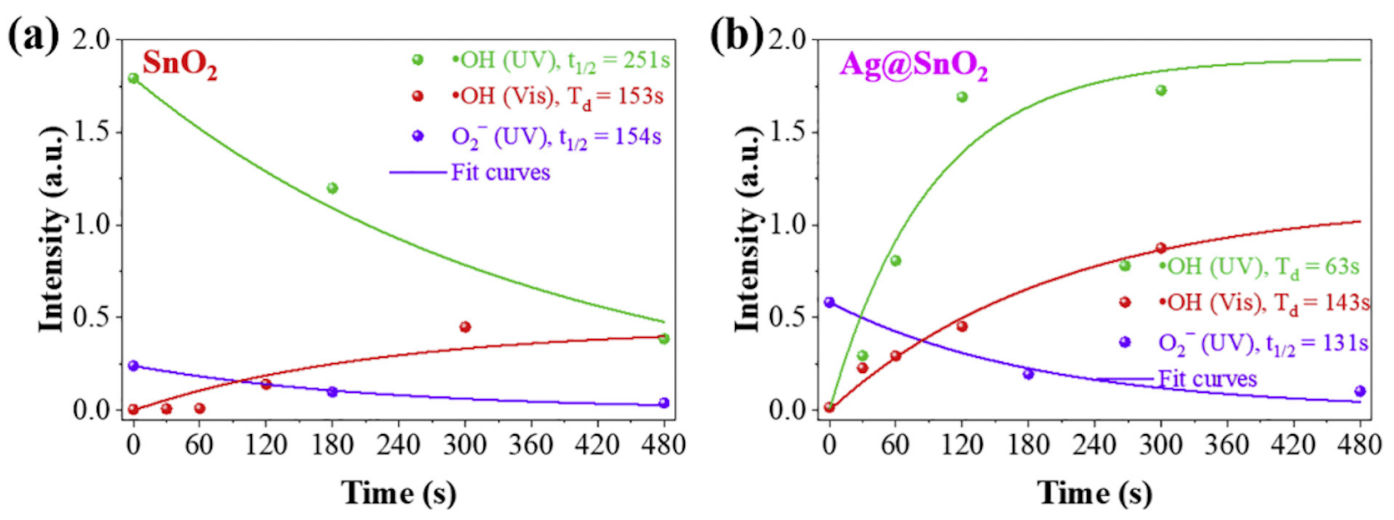

Figure 16: Decay and growth curves of primary $\mathrm{ROS}$ versus radiation time of $\mathrm{SnO}_{2} \mathrm{NPs}$ (a) and $\mathrm{Ag@SnO}$ (b). Figure 16 was reprinted from [72], Catalysis Communications, vol. 136, by Bui, D. P.; Nguyen, M. T.; Tran, H. H.; You, S.-J.; Wang, Y.-F.; Van Viet, P. "Green synthesis of Ag@SnO 2 nanocomposites for enhancing photocatalysis of nitrogen monoxide removal under solar light irradiation", article no. 105902, Copyright (2019), with permission from Elsevier. This content is not subject to CC BY 4.0. 
$75 \%$ under solar light). Also, the syntheses of the materials are difficult to upscale to an industrial scale. Moreover, the photocatalysts were prepared in powder form, which is not suitable for emerging applications. Based on this review, we suggest the following subjects for future research: (1) improving the NO photocatalytic degradation by combining other favorable bandgap semiconductors; (2) constructing a ternary heterostructure to create double $\mathrm{Z}$-scheme/S-scheme materials, preferably using two redox sites; (3) synthesizing other morphologies of $\mathrm{SnO}_{2}$ such as nanorods, nanotubes, or 3D structures to increase the specific surface area of the catalyst; (4) upscaling the syntheses and using other synthesis approaches such as sol-gel or chemical vapor deposition to form thin film materials that can replace powder materials, (5) adhering the catalyst materials on commercial films such as polypropylene, polytetrafluorethylene, or PM2.5 films for real-life applications, such as air filters and $\mathrm{NO}_{x}$ gas treatment membranes; and (6) applying the materials in biological media where the presence of $\mathrm{NO} / \mathrm{NO}_{2}$ is predominant.

\section{Acknowledgements}

The authors sincerely thank the Department of Science and Technology, Ho Chi Minh City, the CM Thi Laboratory, and Mr. Sang T. Truong for support. The authors would also like to thank Elsevier, the American Chemical Society, the American Physical Society, and the Royal Society of Chemistry for allowing us to reuse some of the materials in this work.

\section{ORCID ${ }^{\circledR}$ iDs}

Viet Van Pham - https://orcid.org/0000-0002-8697-7095 Hong-Huy Tran - https://orcid.org/0000-0002-7883-596X

\section{References}

1. WHO Air pollution. https://www.who.int/health-topics/air-pollution\#tab=tab_1 (accessed June 23, 2021).

2. WHO Regional Office for Europe. Chapter 7.1-Nitrogen dioxide; Copenhagen, Denmark, 2000; pp 1-33.

3. United States Environmental Protection Agency. Nitrogen Oxides Control Regulations, Ozone Control Strategies, Ground-level Ozone; New England, 2021.

4. WHO. Ambient (outdoor) air pollution; 2021

5. Health Canada. Residential Indoor Air Quality Guideline: Nitrogen Dioxide. 2015; https://www.canada.ca/en/health-canada/services/publications/healthyliving/residential-indoor-air-quality-guideline-nitrogen-dioxide.html.

6. Chossiere, G. P.; Xu, H.; Dixit, Y.; Isaacs, S.; Eastham, S. D.; Allroggen, F.; Speth, R. L.; Barrett, S. R. H. Sci. Adv. 2021, 7, eabe1178. doi:10.1126/sciadv.abe1178

7. United States Environmental Protection Agency. Nitrogen Oxides (NOx), Why and How They Are Controlled; North Carolina, 1999

8. Haneda, M.; Ota, Y.; Doi, Y.; Hattori, M. J. Mater. Sci. 2016, 51, 10949-10959. doi:10.1007/s10853-016-0307-8
9. Rajta, A.; Bhatia, R.; Setia, H.; Pathania, P. J. Appl. Microbiol. 2020, 128, 1261-1278. doi:10.1111/jam.14476

10. Bogaerts, W. F.; Lampert, C. M. J. Mater. Sci. 1983, 18, 2847-2875. doi:10.1007/bf00700767

11. Zou, J.; Xu, Y.; Hou, B.; Wu, D.; Sun, Y. China Particuol. 2007, 5, 206-212. doi:10.1016/j.cpart.2007.03.006

12. Ângelo, J.; Andrade, L.; Madeira, L. M.; Mendes, A. J. Environ. Manage. 2013, 129, 522-539. doi:10.1016/j.jenvman.2013.08.006

13. Batzill, M.; Diebold, U. Prog. Surf. Sci. 2005, 79, 47-154. doi:10.1016/j.progsurf.2005.09.002

14. He, Z.; Zhou, J. Mod. Res. Catal. 2013, 02, 13-18. doi:10.4236/mrc.2013.23a003

15. Savioli, J.; Gavin, A. L.; Lucid, A. K.; Watson, G. W. The structure and electronic structure of tin oxides. In Tin Oxide Materials; Orlandi, M. O. Ed.; 2020; pp 11-39. doi:10.1016/b978-0-12-815924-8.00002-5

16. Grządziel, L.; Krzywiecki, M. Front. Nanosci. 2019, 14, 215-256. doi:10.1016/b978-0-08-102572-7.00008-8

17. Subramanian, V.; Burke, W. W.; Zhu, H.; Wei, B. J. Phys. Chem. C 2008, 112, 4550-4556. doi:10.1021/jp711551p

18. Xiao, L.; Shen, H.; von Hagen, R.; Pan, J.; Belkoura, L.; Mathur, S. Chem. Commun. 2010, 46, 6509-6511. doi:10.1039/c0cc01156h

19. Kar, A.; Kundu, S.; Patra, A. J. Phys. Chem. C 2011, 115, 118-124. doi:10.1021/jp110313b

20. Birkel, A.; Lee, Y.-G.; Koll, D.; Meerbeek, X. V.; Frank, S.; Choi, M. J.; Kang, Y. S.; Char, K.; Tremel, W. Energy Environ. Sci. 2012, 5, 5392-5400. doi:10.1039/c1ee02115j

21. Priya, S.; Halder, J.; Mandal, D.; Chowdhury, A.; Singh, T.; Chandra, A J. Mater. Sci. 2021, 56, 9883-9893. doi:10.1007/s10853-021-05942-x

22. Wang, Z.; Zhi, M.; Xu, M.; Guo, C.; Man, Z.; Zhang, Z.; Li, Q.; Lv, Y.; Zhao, W.; Yan, J.; Zhai, C. J. Mater. Sci. 2021, 56, 7348-7356. doi:10.1007/s10853-020-05737-6

23. Jiang, S.; Yue, W.; Gao, Z.; Ren, Y.; Ma, H.; Zhao, X.; Liu, Y.; Yang, X. J. Mater. Sci. 2013, 48, 3870-3876. doi:10.1007/s10853-013-7189-9

24. Li, T.-T.; Xia, L.; Yu, H.; Huang, X.-X. J. Mater. Sci. 2020, 55, 11949-11958. doi:10.1007/s10853-020-04892-0

25. Anandan, K.; Rajendran, V. Superlattices Microstruct. 2015, 85 , 185-197. doi:10.1016/j.spmi.2015.05.031

26. Bouras, K.; Rehspringer, J.-L.; Schmerber, G.; Rinnert, H.; Colis, S.; Ferblantier, G.; Balestrieri, M.; Ihiawakrim, D.; Dinia, A.; Slaoui, A. J. Mater. Chem. C 2014, 2, 8235-8243. doi:10.1039/c4tc01202j

27. Yadav, B. C.; Verma, N.; Shukla, T.; Singh, S.; Sabhajeet, S. R. J. Mater. Sci.: Mater. Electron. 2016, 27, 7852-7863. doi:10.1007/s10854-016-4776-y

28. Malik, R.; Tomer, V. K.; Chaudhary, V.; Dahiya, M. S.; Rana, P. S.; Nehra, S. P.; Duhan, S. ChemistrySelect 2016, 1, 3247-3258. doi:10.1002/slct.201600634

29. Enesca, A.; Yamaguchi, Y.; Terashima, C.; Fujishima, A.; Nakata, K.; Duta, A. J. Catal. 2017, 350, 174-181. doi:10.1016/j.jcat.2017.02.015

30. Fan, C.; Song, X.; Yin, Z.; Yu, H.; Sun, S. J. Mater. Sci. 2006, 41, 5696-5698. doi:10.1007/s10853-006-0067-y

31. Li, D.; Huang, J.; Li, R.; Chen, P.; Chen, D.; Cai, M.; Liu, H.; Feng, Y.; Lv, W.; Liu, G. J. Hazard. Mater. 2021, 401, 123257. doi:10.1016/j.jhazmat.2020.123257

32. Dawar, A. L.; Kumar, A.; Sharma, S.; Tripathi, K. N.; Mathur, P. C. J. Mater. Sci. 1993, 28, 639-644. doi:10.1007/bf01151238

33. Kim, S. P.; Choi, M. Y.; Choi, H. C. Mater. Res. Bull. 2016, 74, 85-89. doi:10.1016/j.materresbull.2015.10.024

34. Al-Hamdi, A. M.; Rinner, U.; Sillanpää, M. Process Saf. Environ. Prot. 2017, 107, 190-205. doi:10.1016/j.psep.2017.01.022 
35. Bui, P. D.; Tran, H. H.; Kang, F.; Wang, Y.-F.; Cao, T. M.; You, S.-J.; Vu, N. H.; Pham, V. V. ACS Appl. Nano Mater. 2018, 1, 5786-5794. doi:10.1021/acsanm.8b01445

36. Xie, Y.; Yu, S.; Zhong, Y.; Zhang, Q.; Zhou, Y. Appl. Surf. Sci. 2018, 448, 655-661. doi:10.1016/j.apsusc.2018.04.145

37. Zou, Y.; Xie, Y.; Yu, S.; Chen, L.; Cui, W.; Dong, F.; Zhou, Y. Appl. Surf. Sci. 2019, 496, 143630. doi:10.1016/j.apsusc.2019.143630

38. Huy, T. H.; Bui, D. P.; Kang, F.; Wang, Y.-F.; Liu, S.-H.; Thi, C. M.; You, S.-J.; Chang, G.-M.; Pham, V. V. Chemosphere 2019, 215, 323-332. doi:10.1016/j.chemosphere.2018.10.033

39. Song, X.; Qin, G.; Cheng, G.; Jiang, W.; Chen, X.; Dai, W.; Fu, X. Appl. Catal., B 2021, 284, 119761. doi:10.1016/j.apcatb.2020.119761

40. Islam, M. H.; Hogarth, C. A.; Lott, K. A. J. Mater. Sci. 1989, 24 , 1305-1308. doi:10.1007/pl00020212

41. Dou, M.; Persson, C. J. Appl. Phys. 2013, 113, 083703. doi:10.1063/1.4793273

42. Zhou, W.; Liu, Y.; Yang, Y.; Wu, P. J. Phys. Chem. C 2014, 118, 6448-6453. doi:10.1021/jp500546r

43. Yu, H.; Wang, S.; Xiao, C.; Xiao, B.; Wang, P.; Li, Z.; Zhang, M. CrystEngComm 2015, 17, 4316-4324. doi:10.1039/c5ce00448a

44. Entradas, T.; Cabrita, J. F.; Dalui, S.; Nunes, M. R.; Monteiro, O. C.; Silvestre, A. J. Mater. Chem. Phys. 2014, 147, 563-571. doi:10.1016/j.matchemphys.2014.05.032

45. Mounkachi, O.; Salmani, E.; Lakhal, M.; Ez-Zahraouy, H.; Hamedoun, M.; Benaissa, M.; Kara, A.; Ennaoui, A.; Benyoussef, A. Sol. Energy Mater. Sol. Cells 2016, 148, 34-38. doi:10.1016/j.solmat.2015.09.062

46. Babu, B.; Neelakanta Reddy, I.; Yoo, K.; Kim, D.; Shim, J. Mater. Lett. 2018, 221, 211-215. doi:10.1016/j.matlet.2018.03.107

47. Fan, C.-M.; Peng, Y.; Zhu, Q.; Lin, L.; Wang, R.-X.; Xu, A.-W. J. Phys. Chem. C 2013, 117, 24157-24166. doi:10.1021/jp407296f

48. Batzill, M.; Katsiev, K.; Burst, J. M.; Diebold, U.; Chaka, A. M.; Delley, B. Phys. Rev. B 2005, 72, 165414. doi:10.1103/physrevb.72.165414

49. Van Viet, P.; Huy, T. H.; Sang, N. X.; Thi, C. M.; Van Hieu, L. J. Mater. Sci. 2018, 53, 3364-3374. doi:10.1007/s10853-017-1762-6

50. Van Viet, P.; Thi, C. M.; Hieu, L. V. J. Nanomater. 2016, 2016, 1-8. doi:10.1155/2016/4231046

51. Nam, V. H.; Van Viet, P.; Van Hieu, L.; Thi, C. M. Mater. Res. Express 2016, 3, 105901. doi:10.1088/2053-1591/3/10/105901

52. Zhong, Y.; Li, W.; Zhao, X.; Jiang, X.; Lin, S.; Zhen, Z.; Chen, W.; Xie, D.; Zhu, H. ACS Appl. Mater. Interfaces 2019, 11, 13441-13449. doi:10.1021/acsami.9b01737

53. Mäki-Jaskari, M. A.; Rantala, T. T.; Golovanov, V. V. Surf. Sci. 2005, 577, 127-138. doi:10.1016/j.susc.2005.01.004

54. Xu, G.; Zhang, L.; He, C.; Ma, D.; Lu, Z. Sens. Actuators, B 2015, 221, 717-722. doi:10.1016/j.snb.2015.06.143

55. Tiya-Djowe, A.; Dourges, M.-A.; Deleuze, H. J. Mater. Sci. 2020, 55, 4792-4807. doi:10.1007/s10853-019-04335-5

56. Wang, M.; Gao, Y.; Dai, L.; Cao, C.; Guo, X. J. Solid State Chem. 2012, 189, 49-56. doi:10.1016/j.jssc.2012.01.021

57. Jain, K.; Shrivastava, A.; Rashmi, R. ECS Trans. 2006, 1 (21), 1-7. doi:10.1149/1.2218985

58. Zhao, Q.; Ju, D.; Deng, X.; Huang, J.; Cao, B.; Xu, X. Sci. Rep. 2015, 5, 7874. doi:10.1038/srep07874

59. Talebian, N.; Jafarinezhad, F. Ceram. Int. 2013, 39, 8311-8317. doi:10.1016/j.ceramint.2013.03.101

60. Park, M.-S.; Kang, Y.-M.; Wang, G.-X.; Dou, S.-X.; Liu, H.-K. Adv. Funct. Mater. 2008, 18, 455-461. doi:10.1002/adfm.200700407
61. Nahirniak, S.; Dontsova, T.; Dusheiko, M.; Smertenko, P.; Kwapinski, W. J. Mater. Sci.: Mater. Electron. 2020, 31, 21934-21947. doi:10.1007/s10854-020-04697-6

62. Matysiak, W.; Tański, T.; Smok, W.; Polishchuk, O. Sci. Rep. 2020, 10, 14802. doi:10.1038/s41598-020-71383-2

63. Shen, Y.; Wang, W.; Fan, A.; Wei, D.; Liu, W.; Han, C.; Shen, Y.; Meng, D.; San, X. Int. J. Hydrogen Energy 2015, 40, 15773-15779. doi:10.1016/j.ijhydene.2015.09.077

64. Chu, D.; Mo, J.; Peng, Q.; Zhang, Y.; Wei, Y.; Zhuang, Z.; Li, Y. ChemCatChem 2011, 3, 371-377. doi:10.1002/cctc.201000334

65. Pijolat, C.; Riviere, B.; Kamionka, M.; Viricelle, J. P.; Breuil, P. J. Mater. Sci. 2003, 38, 4333-4346. doi:10.1023/a:1026387100072

66. Wang, Y.-F.; Lei, B.-X.; Hou, Y.-F.; Zhao, W.-X.; Liang, C.-L.; Su, C.-Y.; Kuang, D.-B. Inorg. Chem. 2010, 49, 1679-1686. doi:10.1021/ic902092e

67. Le, T. H.; Truong, Q. D.; Kimura, T.; Li, H.; Guo, C.; Yin, S.; Sato, T.; Ling, Y.-C. Solid State Sci. 2013, 15, 29-35. doi:10.1016/j.solidstatesciences.2012.09.004

68. Zhang, L.; Tong, R.; Shirsath, S. E.; Yang, Y.; Dong, G. J. Mater. Chem. A 2021, 9, 5000-5006. doi:10.1039/d0ta12101k

69. Huy, T. H.; Phat, B. D.; Thi, C. M.; Van Viet, P. Environ. Chem. Lett. 2019, 17, 527-531. doi:10.1007/s10311-018-0801-0

70. Wu, H.; Yuan, C.; Chen, R.; Wang, J.; Dong, F.; Li, J.; Sun, Y. ACS Appl. Mater. Interfaces 2020, 12, 43741-43749. doi:10.1021/acsami.0c12628

71. Van Pham, V.; Mai, D.-Q.; Bui, D.-P.; Van Man, T.; Zhu, B.; Zhang, L.; Sangkaworn, J.; Tantirungrotechai, J.; Reutrakul, V.; Cao, T. M. Environ. Pollut. 2021, 286, 117510. doi:10.1016/j.envpol.2021.117510

72. Bui, D. P.; Nguyen, M. T.; Tran, H. H.; You, S.-J.; Wang, Y.-F.; Van Viet, P. Catal. Commun. 2020, 136, 105902. doi:10.1016/j.catcom.2019.105902

73. Van Viet, P.; Nguyen, T.-D.; Bui, D.-P.; Thi, C. M. J. Materiomics 2022, 8, 1-8. doi:10.1016/j.jmat.2021.06.006

74. Zhang, T.; Xu, J.; Qian, J.; Zhang, J. J. Mater. Sci. 2020, 55, 13605-13617. doi:10.1007/s10853-020-04998-5

75. Li, Y.; Wu, X.; Ho, W.; Lv, K.; Li, Q.; Li, M.; Lee, S. C. Chem. Eng. J. 2018, 336, 200-210. doi:10.1016/j.cej.2017.11.045

76. Lu, Y.; Huang, Y.; Cao, J.-j.; Li, H.; Ho, W.; Lee, S. C. J. Mater. Chem. A 2019, 7, 15782-15793. doi:10.1039/c9ta03504d

77. Kamble, V. B.; Umarji, A. M. AIP Adv. 2013, 3, 082120. doi:10.1063/1.4819451

78. Manjula, P.; Arunkumar, S.; Manorama, S. V. Sens. Actuators, B 2011, 152, 168-175. doi:10.1016/j.snb.2010.11.059

79. Zhang, K.; Yang, X.; Wang, Y.; Bing, Y.; Qiao, L.; Liang, Z.; Yu, S.; Zeng, Y.; Zheng, W. Sens. Actuators, B 2017, 243, 465-474. doi:10.1016/j.snb.2016.11.153 


\section{License and Terms}

This is an open access article licensed under the terms of the Beilstein-Institut Open Access License Agreement (https://www.beilstein-journals.org/bjnano/terms), which is identical to the Creative Commons Attribution 4.0 International License

(https://creativecommons.org/licenses/by/4.0). The reuse of material under this license requires that the author(s), source and license are credited. Third-party material in this article could be subject to other licenses (typically indicated in the credit line), and in this case, users are required to obtain permission from the license holder to reuse the material.

The definitive version of this article is the electronic one which can be found at:

https://doi.org/10.3762/bjnano.13.7 